\title{
WP 16-21
}

\author{
Guido Matias Cortes \\ University of Manchester, UK \\ The Rimini Centre for Economic Analysis, Italy
}

Andrea Salvatori

University of Essex, UK

\section{DELVING INTO THE DEMAND SIDE: ChangeS IN WORKPLACE SPECIALIZATION AND Job Polarization}

Copyright belongs to the author. Small sections of the text, not exceeding three paragraphs, can be used provided proper acknowledgement is given.

The Rimini Centre for Economic Analysis (RCEA) was established in March 2007. RCEA is a private, nonprofit organization dedicated to independent research in Applied and Theoretical Economics and related fields. RCEA organizes seminars and workshops, sponsors a general interest journal The Review of Economic Analysis, and organizes a biennial conference: The Rimini Conference in Economics and Finance (RCEF). The RCEA has a Canadian branch: The Rimini Centre for Economic Analysis in Canada (RCEACanada). Scientific work contributed by the RCEA Scholars is published in the RCEA Working Papers and Professional Report series.

The views expressed in this paper are those of the authors. No responsibility for them should be attributed to The Rimini Centre for Economic Analysis. 


\title{
Delving into the Demand Side: Changes in Workplace Specialization and Job Polarization
}

\author{
Guido Matias Cortes \\ Andrea Salvatori \\ University of Manchester and RCEA* \\ ISER, University of Essex and $\mathrm{IZA}^{\dagger}$
}

August 1, 2016

\begin{abstract}
** This paper offers the first study of job polarization in Great Britain using workplace level data. We document widespread and increasing occupational specialization within establishments, along with substantial heterogeneity in specialization within industries. Changes in the specialization profiles of workplaces account for most of the changes in the aggregate occupational shares between 1998 and 2011. The sharp rise in the fraction of workplaces specializing in nonroutine tasks is associated with a large increase in the concentration of non-routine workers in workplaces that specialize in such occupations. We find no evidence of a decline in routine employment among establishments that report the adoption of new technologies, as would be expected from the standard routine-biased technological change hypothesis. Instead, we uncover new evidence that suggests that the increase in non-routine cognitive workplaces is linked to the growth in outsourcing of cognitive tasks.
\end{abstract}

*E-mail: matias.cortes@manchester.ac.uk.

${ }^{\dagger}$ E-mail: asalva@essex.ac.uk. Andrea Salvatori thanks the UK Economic and Social Research Council (ESRC) for support under the grant "Job Polarisation and Job Quality" (grant ES/K001116/1) and through the Research Centre on Micro-Social Change (MiSoC) at the University of Essex, grant number ES/L009153/1. We thank Alex Bryson, Maarten Goos, Rachel Griffith, Ariell Reshef and Anna Salomons for very helpful comments and suggestions. We also thank participants at the AEA and RES Conferences, and at seminars at Essex, La Sapienza, Utrecht, IAAEU Trier and the Atlanta Fed.

${ }^{* *}$ For the latest version of the paper check here or go to https://goo.gl/9QHOxB 


\section{Introduction}

In recent decades labor markets in many developed countries have become increasingly polarized: the share of employment in middle-wage occupations has declined, while employment in both high- and low-wage occupations has increased Acemoglu and Autor, 2011). The existing literature points to increasing automation and offshoring of routine middling jobs as the main drivers of this phenomenon (e.g. Autor et al. 2006, 2008; Acemoglu and Autor, 2011; Firpo et al., 2011; Goos et al., 2014). These explanations emphasize changes in labor demand which would be directly reflected in changes in firm behavior. However, there is very limited evidence on occupational adjustments at the firm level, as the vast majority of the polarization literature relies on individual or aggregate-level data (e.g. Spitz-Oener, 2006; Goos and Manning, 2007; Autor et al., 2015; Autor and Dorn, 2013; Michaels et al., 2014; Cortes, 2016).

While abstracting from adjustments at the firm level may be innocuous if firms are homogeneous, a separate strand of the literature shows that firm heterogeneity is an increasingly important feature of the labor market. Studies have shown that productivity differences are widespread even within narrowly defined industries (Bartelsman and Doms, 2000; Griffith et al., 2006; Bloom and Van Reenen, 2011; Melitz and Redding, 2014), while a number of papers show that wage differences across (rather than within) firms account for most of the recent change in wage inequality Card et al. 2013; Song et al., 2015; Barth et al., 2016; Helpman et al., 2016). This increase in heterogeneity has been linked to higher specialization of firms due to organizational change (Handwerker and Spletzer, 2016; Goldschmidt and Schmieder, 2015) and to differential adoption and use of technology driven by differences in managerial practices across firms (Bloom and Van Reenen, 2011).

This paper offers the first analysis of changes in the occupational structure at the workplace level in Great Britain. We use three waves of the Workplace Employment Relations Survey (WERS) covering a representative sample of establishments between 1998 and 2011. So far there is very little evidence on how establishments are organized in terms of the occupation or task structure that has been emphasized by the polarization literature $1^{1}$ Our analysis fills this gap and offers a rich new set of facts on the task composition of establishments, providing fresh insights on potential mechanisms and

\footnotetext{
${ }^{1} \mathrm{An}$ active strand of the literature analyzes the composition of firms in terms of hierarchical layers (rather than tasks) both theoretically and empirically; see for example Garicano and Rossi-Hansberg (2006) and Caliendo et al. (2015).
} 
implications of job polarization and on the increase in heterogeneity between firms documented in the literature.

Our first contribution is to show that British establishments are highly specialized in terms of their task composition. 90\% of private sector establishments in 2011 employ at least half of their workers in one of four broad task groups. We show that this is not driven by small workplaces or by the division of work across establishments of larger organizations. Strikingly, over $60 \%$ of the variation in specialization is concentrated within industries. The occupational mix that is observed at the industry level is therefore the result of the aggregation across a very heterogeneous set of workplaces, rather than being informative about a "representative" firm. This puts into question the common assumption made in the polarization literature of homogeneity in technology within industries, which is a crucial assumption in order to interpret within-industry changes as reflecting changes in technology rather than changes in output mix.2 ${ }^{2}$

Our next contribution is to document striking changes in the specialization profile of British workplaces in recent times. We show both a decline in the fraction of nonspecialized establishments and an increase in the fraction of employment concentrated in the main task among specialized establishments, including in those specialized in routine tasks. The proportion of workplaces specializing in a non-routine task increases from $30 \%$ to $50 \%$ between 1998 and 2011. A decomposition shows that these changes in the population of establishments in terms of their task specialization account for most of the changes in aggregate occupational shares, both overall and within industries. These changes have an important implication: polarization in Great Britain has been associated with a substantial shift in the distribution of non-routine employment both cognitive and manual - towards workplaces that specialize in these tasks. For example, the proportion of non-routine cognitive employment found in establishments specializing in such occupations rose from $47 \%$ in 1998 to $67 \%$ in 2011. Existing studies have highlighted the fact that examining the consequences of polarization for inequality is complicated by the reallocation of skill groups across tasks Acemoglu and Autor. 2011). This finding adds an additional dimension to the problem since it shows that the polarization of the labor market has also been accompanied by an important change in the distribution of employment of different occupations across different types of

\footnotetext{
${ }^{2}$ For a recent discussion of these issues in the context of firms' responses to local labor supply shocks, see Dustmann and Glitz (2015). Goos et al. (2014) are an example of a paper on job polarization in which the distinction between changes between and within 1-digit industries have substantive implications.
} 
firms which, as highlighted in the literature on firm heterogeneity discussed above, has potentially important implications for workers' outcomes..$^{3}$

Our data do not allow us to provide direct causal evidence on the role of routinebiased technological change (RBTC) in driving the workplace-level changes that we have documented. However, we are able to exploit some unique features of WERS to investigate the presence of some of the underlying mechanisms put forward in this literature. Using direct measures of technology adoption at the establishment level, we find no support for the hypothesis that the net impact of technology adoption on workplace employment is negative, either in general or among workplaces specializing in routine tasks. This suggests that any productivity-enhancing effects of technology which increase the scale of the firm outweigh the labor-replacing effect of technology. Relatedly, we find that very few workplaces report redundancies due to automation when asked directly. These results are in line with those of recent studies that find no indication of a negative effect of technology on employment levels using occupation, industry and individual level data (Bessen, 2015; Graetz and Michaels, 2015; Gaggl and Wright, 2015).

We also find several pieces of evidence that point towards a growing importance of technology in workplaces specializing in non-routine manual occupations, which are generally assumed to offer limited scope for either complementarity or substitutability between technology and labor $4^{4}$ In particular, we find that these workplaces experience the largest increase in the proportion reporting the adoption of new technology before the recession, and the share of employees using computers in these workplaces more than doubles (from 16\% to over 33\%) in just seven years between 2004 and 2011. Another intriguing finding is that, across workplaces of all specializations, the adoption of new technology is correlated with a subsequent decline in the establishment's share of non-routine manual employment. A similar association is not present when focusing on the share of employment in routine occupations, which are typically thought of as being the most highly susceptible to automation.

Technology may be influencing the changes in occupational specialization at the workplace level through mechanisms other than those emphasized by the RBTC hy-

\footnotetext{
${ }^{3}$ These changes may also have impacts on worker outcomes due to the importance of peer effects; see for example Mas and Moretti (2009) for empirical evidence on the importance of peer effects in the workplace.

${ }^{4}$ For example, in Autor and Dorn (2013), technology only affects these occupations indirectly through the complementarity in consumption between services and goods. See also Mazzolari and Ragusa (2013).
} 
pothesis. As Abramovsky and Griffith (2006) show, ICT adoption can increase the incentives for firms to acquire services externally, rather than producing them internally, due to the reduction in transaction and monitoring costs. We exploit another unique feature of WERS to provide new evidence on the extent to which different types of establishments outsource certain tasks, or engage in the provision of such tasks to other businesses 5

Over our sample period, we find no indication of the increase in outsourcing of lowskill services that has been the main focus of the literature on the effects of outsourcing on inequality (e.g. Dube and Kaplan, 2010; Goldschmidt and Schmieder, 2015). Instead, we document a sharp increase in the share of workplaces using contractors for cognitive activities alongside an increase in the proportion of non-routine cognitive workplaces trading with other businesses, especially among new entrants. The overall incidence of the business-to-business sector has not increased, but its composition in terms of the occupational specialization of workplaces has changed significantly. The business-tobusiness sector accounts for the entire increase in the fraction of specialized workplaces in the aggregate as well as for most of the increase in the share of non-routine cognitive workplaces. In fact, the proportion of non-routine cognitive workplaces within the business-to-business sector increased by over $70 \%$ in just seven years. Hence, while the existing literature has mainly focused on the contribution of international offshoring to job polarization, our results strongly suggest that domestic outsourcing of cognitive services is likely to have played a central role in defining some of the key workplace-level features of polarization in Great Britain.

Our paper is part of an emerging literature on the establishment-level patterns underlying job polarization. Böckerman et al. (2016) and Pekkala Kerr et al. (2015) use panel data from Finland to analyze the importance of within and between firm changes in contributing to the overall changes in the occupational composition of the economy. Harrigan et al. (2015) develop a new measure of the propensity of firms to adopt new technologies, and use administrative data from France to analyze the link between this measure and changes in the occupational composition of employment within firms. Our results complement the findings from these recent papers by emphasizing the pervasiveness of specialization within establishments and by showing how changes over time in the specialization patterns are linked to the polarization of employment observed at

\footnotetext{
${ }^{5}$ While the availability of low-cost technology is widely recognized as a factor facilitating outsourcing, the literature has considered several other potential drivers of firms' outsourcing decisions. See among others Abraham and Taylor (1996); Sako (2006).
} 
the aggregate level. Moreover, the exploration of the role of increasing trade in cognitive tasks between firms is a distinctive contribution of this paper which also speaks to the literature on the importance of organizational changes for the composition of employment (Caroli and Van Reenen, 2001; Green, 2012).

\section{Data and occupational shares}

We use data from three cross-sections of the British Workplace Employment Relations Survey (WERS) of 1998, 2004, and 2011 (BIS, 2015). The survey covers a representative sample of workplaces in Great Britain in all sectors of the economy except agriculture and mining. We restrict our attention to establishments with at least 10 employees - the minimum employment thresholds in the 1998 wave ${ }^{6}$ We use data from the Management Questionnaires, which provide a wide range of establishment characteristics, including the composition of employment within the workplace..$^{7}$

The weighted WERS sample is representative of $35 \%$ of all workplaces in Britain in 2011, due to the exclusion of small workplaces. However, the included workplaces are representative of $90 \%$ of total employment, so changes in these establishments will clearly be the main drivers of changes in the overall employment patterns of the economy. Appendix A provides further details about the weights available in WERS.

The survey also includes a sample of about 900 establishments which are interviewed in two consecutive waves. While most of our analysis is based on the cross-sectional samples, we exploit this limited panel dimension in some of our analysis in order to provide evidence of longitudinal changes occurring within workplaces.

Crucially for our analysis, managers are asked about the composition of employment within the workplace across nine occupational groups. In each year, managers were provided with descriptions of each occupational group and these descriptions are highly consistent over time, as we discuss in Appendix B. For ease of presentation and to facilitate the comparison with much of the earlier literature, we group these nine occupations following Acemoglu and Autor (2011) according to their prevailing task

\footnotetext{
${ }^{6}$ We check the robustness of our results (when possible) to the use of workplaces with more than 5 employees.

${ }^{7}$ We use the terms "workplace" and "establishment" interchangeably. A workplace - which is our unit of observation - is defined as an enterprise or part thereof (for example a workshop, factory, warehouse, office, mine or depot) situated in a geographically identified place. A workplace comprises the activities of a single employer at a single set of premises. More information about the survey can be found at http://www.wers2011.info/.
} 
content. We check that our main results are not driven by this level of aggregation, as we report at several points in the paper. The groups are:

1. Non-routine cognitive (NRC): Managers; Professionals; Technicians.

2. Routine cognitive (RC): Administrative and secretarial occupations, Sales and customer service occupations.

3. Routine manual (RM): Skilled trades occupations; Process, plant and machine operatives and drivers.

4. Non-routine manual (NRM): Caring, leisure and other personal service occupations; Other unskilled occupations.

Table 1 presents the aggregate share of employment in each of these four occupational groups obtained from our dataset (using establishments with at least 10 employees). Panel A shows that, between 1998 and 2011, routine employment declines entirely because of the decline in routine manual employment, which loses about 10pp from the initial level of about $23 \%$. This is mostly compensated by the growth of non-routine cognitive occupations, which gain 8pp, reaching just under 39\% of employment in 2011. The share of employment in non-routine manual occupations is stable at around one fifth of total employment.

Panels B and C consider the composition of employment in the public and private sector separately. The polarization pattern appears clearly only in the private sector. In this sector, non-routine employment gained 14pp due to the growth in both cognitive and manual jobs. The largest expansion is again in non-routine cognitive occupations which climbed from $24 \%$ to $45 \%$ between 1998 and 2011. The decline in routine employment is entirely driven by manual occupations as we saw in the overall economy, but in this sector the share of routine cognitive employment did not increase. For the remainder of the paper we focus on the private sector - which represents over $70 \%$ of overall employment in our sample - as the explanations that have been proposed in the literature for job polarization appear to be most relevant for this sector.

Overall, the results that (i) routine employment has declined mainly because of a decline in routine manual employment and (ii) that this is mostly compensated by an increase in non-routine cognitive employment, are both in line with the patterns presented in Salvatori (2015) using UK Labour Force Survey data on all workers for roughly the same time period. This confirms the reliability of our data in capturing 
these key aggregate employment trends, enabling their analysis from an establishmentlevel perspective. The main difference with the findings from nationally representative data lies in the fact that Salvatori (2015) reports that routine cognitive employment has also lost in employment share, while the WERS data show that this has not been the case in workplaces with at least 10 employees. In Appendix Table A.1 we show that the increase in routine cognitive employment is due entirely to the growth of sales occupations, while clerical occupations have lost shares.$^{8}$

\section{Task specialization of establishments}

This section provides new evidence on the occupational composition of employment within establishments. We begin by documenting patterns of occupational specialization across workplaces and their changes over time. We classify an establishment as being specialized if more than $50 \%$ of its employment is concentrated in one of the four broad categories described above. This ensures that a workplace can only be specialized in one occupational group. Below we discuss the robustness of our results to alternative ways of measuring specialization.

Panel A of Table 2 provides an interesting picture of the specialization patterns across private sector establishments and how these change over time. Columns (1) to (3) show the fraction of establishments with different types of specialization for each of the three years in the sample. A first striking result is that over $83 \%$ of establishments are specialized in one of the four occupational groups according to our measure of specialization. For example, in 2011 only $12 \%$ of establishments employed a mix of workers where less than half were in one of the four occupational groups. This high degree of establishment specialization is not driven by small establishments, as shown in Columns (4) to (6), where results are weighted by employment; specialized establishments comprise the vast majority of overall employment.

Table 2 also shows how the specialization profile of these workplaces has changed over our sample period. First, we note that specialization has increased over time: we observe a decline both in the fraction of establishments that are non-specialized (from $17 \%$ if 1998 to $12 \%$ in 2011) and in the fraction of employment that these establishments account for (from 16\% in 1998 to $10 \%$ in 2011). Second, there is a very pronounced

\footnotetext{
${ }^{8}$ Using LFS data, Salvatori (2015) reports that the employment share in clerical occupations falls by about 2 pp during the 2000s, while the employment share of sales occupations remains roughly constant.
} 
shift in specialization towards non-routine occupations, with the fraction of workplaces specialized in these occupations increasing from 30\% in 1998 to $49 \%$ in 2011, amounting to a proportional increase of over 60 percent. The fraction of employment accounted for by such workplaces also rose sharply from $31 \%$ to $51 \%$. Interestingly, the decline in the fraction specializing in routine occupations involves both cognitive and manual establishments, even though only the aggregate share of routine manual employment declines, as seen in Table 1. The stability of the employment share accounted for by workplaces specialized in routine cognitive occupations indicates that the average size of these workplaces has gone up. Hence, overall, we see a much more pronounced polarization pattern in terms of workplace specialization than we see in terms of aggregate employment shares. We return to the link between changes in specialization patterns and changes in aggregate shares in Section 3.3 .

The results just discussed are not driven by the division of work across workplaces belonging to larger organizations. This can be seen in Panel B of Table 2 which considers the $40 \%$ of workplaces in our sample which are not part of larger organizations. These independent establishments are also very specialized and, while they start from higher levels of specialization in routine manual occupations, the major patterns in terms of changes in specialization are similar to the ones observed for the private sector as a whole. In particular, we see a sharp decline in specialization in routine tasks (from $52 \%$ to $37 \%$ ) and a corresponding increase in specialization in non-routine tasks (from $34 \%$ to $50 \%$ ). The fraction of non-specialized workplaces also decreases slightly (from $14.1 \%$ to $13.8 \%$ ), although less than for the whole sample.

Our results also hold when considering specialization patterns at the 1-digit occupation level, as we show in Appendix Table A.2. By this measure, the fraction of non-specialized establishments declines from 33\% to $28 \%$ between 1998 and 2011. The fraction of establishments specializing in each of the routine occupations (including cognitive ones) also declines $!^{9}$ while the fraction specializing in each of the non-routine ones increases (with the exception of managerial occupations - which represent over $50 \%$ of employment in very few workplaces). Finally, we also find evidence of increasing occupational specialization when using a continuous measure of occupational concentration as in Handwerker and Spletzer (2016). In particular, for the median establishment in our sample, the Herfindahl index increases from 0.46 in 1998 to 0.49 in 2004 and 0.51 in 2011.

\footnotetext{
${ }^{9}$ Among workplaces specialized in routine cognitive occupations, the total share of employment only increases for sales workplaces, while it decreases for establishments specialized in clerical occupations.
} 
Figure 1 shows the composition of employment by occupation for establishments with different specializations. The employment share of the largest occupational group ranges between $71 \%$ and $80 \%$ in specialized establishments confirming the extent to which employment is concentrated in the main occupational group across establishments. Specialized establishments are, if anything, becoming even more specialized over time, in the sense that the fraction of employment in their largest occupational group increases between 1998 and 2011. On average across all establishments (including the non-specialized ones), the fraction of employment in the largest occupational group increases slightly from $70 \%$ in 1998 to $73 \%$ in 2011.10 Interestingly, the share of the largest occupation does not decline in workplaces specializing in routine occupations either. We return to this result in Section 4, when we consider how the routine-biased technological change hypothesis relates to our findings.

One important implication of the increased specialization in non-routine occupations documented in this section is that polarization in Great Britain has been associated with a substantial shift in the distribution of non-routine employment - both cognitive and manual - towards workplaces that specialize in these occupations. The proportion of non-routine cognitive workers who are employed in establishments specializing in such occupations increases from 47\% in 1998 to $67 \%$ in 2011. For non-routine manual occupations, the change in the fraction of employees in workplaces specialized in their own occupation is also large, from $67 \%$ to $80 \%$. On the other hand, the proportion of routine workers found in workplaces specialized in their own occupations is more stable (at about $60 \%$ for cognitive occupations and $75 \%$ for manual ones). This reallocation of workers across different types of establishments adds an additional dimension to the complex relationship between job polarization and changes in inequality. Existing studies have emphasized that technological change may induce the reallocation of skill groups across occupations. Here we show that it may also induce reallocation of workers across different types of firms. Given the evidence on the importance of firm heterogeneity in the labor market, this type of reallocation will have important implications for worker outcomes and for overall inequality.

\footnotetext{
${ }^{10}$ The average share of the largest 1-digit occupation also increases from $62 \%$ to $64 \%$.
} 


\subsection{Changes in specialization of surviving establishments and the role of entry and exit}

Changes in the fraction of workplaces specializing in different tasks may be due to changes among continuing establishments, or to differential specialization among entering and exiting establishments. Given the lack of suitable longitudinal data covering the whole period of interest, we exploit the information available from the cross-sectional datasets on the age of the establishments and their survival at the time of the next wave in order to gain some insights on the relative importance of these different channels 11 Table 3 contrasts the specialization profile of entering, exiting and continuing establishments across the three time periods. Column (1) considers exiting establishments, defined as those that were in existence in the base period (1998 in Panel A and 2004 in Panel B), but are no longer in business by the time of the next wave of the survey. Exiting establishments represent approximately $18 \%$ of all establishments in each period. Column (2) considers new establishments, which are defined as those that report having been in operation for less than 6 years in 2004, or less than 7 years in 2011 (the time interval between survey waves). They represent $15 \%$ of all establishments in 2004 and $24 \%$ in 2011.

Contrasting the shares in Column (1) to those for the whole private sector in Table 2 shows that establishments that shut down between surveys are disproportionately likely to be non-specialized or to specialize in one of the manual tasks. In both periods, the largest fraction of exiting workplaces is accounted for by routine manual ones (31\% for 1998-2004 and 24\% for 2004-2011). The specialization profile of exiting establishments is also quite different from that of new establishments. In particular, new establishments are less likely to be non-specialized and much more likely to specialize in non-routine tasks compared to establishments that exit the market. The fraction of routine manual workplaces is higher among exiting than among new workplaces in both periods, but the opposite is true for routine cognitive workplaces. In fact, routine cognitive workplaces account for about a quarter of new entries in both periods and constitute the largest group of new entrants over 2004-2011 (at 26\%) ${ }^{12}$

\footnotetext{
${ }^{11}$ All workplaces included in each cross-section of WERS are recontacted at the time of the following wave to establish whether they are still in operation. The response rate to the follow-up questionnaires is above $98.5 \%$.

${ }^{12}$ The breakdown by specialization at the 1-digit occupation level reveals that in the first period workplaces specializing in both routine cognitive occupations account for more entries and exits, while in the second period this is only the case for workplaces specializing in sales occupations.
} 
In Columns (3) and (4) of Table 3 we analyze the changes in specialization profiles occurring among continuing establishments. Column (3) presents the specialization composition in the base year for establishments that are still in operation by the time of the next survey wave, while Column (4) presents the specialization composition at the time of the next survey wave for establishments that have been in operation at least since the time of the previous survey ${ }^{13}$ In both periods we see a decline in the proportion specializing in routine tasks. This is compensated by an increase in both non-routine and non-specialized workplaces between 1998 and 2004, and by a clearer shift towards specialization in non-routine tasks between 2004 and 2011. Also, the more recent interval stands out for the sharp reduction in specialization in routine cognitive tasks: the fraction specializing in routine cognitive tasks drops by almost a third among continuing establishments, from $32 \%$ in 2004 to $22 \%$ in 2011.

Overall, therefore, the rise in the fraction of establishments specializing in nonroutine tasks is sustained by both entry of new establishments and changes among continuing establishments (with some differences between the two periods). The drivers of the changes in the share specializing in routine occupations, on the other hand, differ more markedly between the manual and cognitive groups. For routine manual workplaces, the evidence indicates that high exit rates play an important role in driving their share down. For routine cognitive establishments, we observe both a decline in their share among continuing establishments, and higher shares among new entrants than among exiting workplaces in both periods.

\subsection{Explaining variation in task specialization across work- places}

This section explores the extent to which industry and workplace characteristics can account for the variation in specialization across workplaces and over time which we have documented. We begin by considering the differences between two broadly defined private sector industries, namely manufacturing and services. Unsurprisingly, as shown in Table 4, manufacturing is characterized by a large fraction of workplaces specializing in routine manual tasks. However, a non-negligible fraction of establishments specialize in other tasks as well. We observe a considerable increase in the fraction of workplaces

\footnotetext{
${ }^{13}$ Although we do not observe the same set of establishments in the two periods, the representativeness of the sample through the use of establishment weights ensures that these figures are comparable and informative about the changes occurring among continuing establishments.
} 
specializing in non-routine cognitive employment, as their share increases more than two and half times from $6 \%$ in 1998 to $16 \%$ in 2011 . While in manufacturing the proportion of non-specialized workplaces has remained stable at around $22 \%$, in services the equivalent figure has fallen from just over $15 \%$ to $11 \%$. At the same time, routine cognitive workplaces have gone from being the largest group in the service sector (at $34 \%$ ) to accounting for roughly the same fraction of workplaces as non-routine cognitive and non-routine manual ones, at around 26\%. The largest proportional increase in the service sector is seen for non-routine manual workplaces, whose share increases by almost 60 percent. Hence, the evidence points to an increase in heterogeneity in specialization within both of these two broad sectors.

To account more formally for the extent of variation in specialization patterns within and between industries, we estimate a series of regressions of the different specialization indicators on a full set of 2-digit industry dummies. The $R^{2}$ from these regressions ranges between 0.32 and 0.39 , implying that more than $60 \%$ of the variation in specialization occurs across establishments within 2-digit industries. This is an important finding, as it implies that the occupational mix that is observed at the industry level is due to the aggregation of employment across a heterogeneous set of workplaces, rather than being informative about a "representative" firm. It is a common practice in the literature to assume that firms within a given industry use similar technology and therefore changes observed within industries are generally interpreted as reflecting changes in technology rather than changes in output mix ${ }^{14}$ Our findings caution against this interpretation.

In Table 5 we report the results from pooled OLS regressions of the specialization indicators on the industry dummies and a set of workplace characteristics. The extra regressors (establishment age, size and region) do not offer much additional explanatory power over and above the industry dummies, indicating that a large amount of heterogeneity in specialization exists within cells defined by these establishment characteristics 15

The coefficients on the time dummies show that the reduction in the conditional probability of specializing in routine tasks and the increase in the conditional probability of specializing in non-routine tasks between 1998 and 2011 are large and statistically significant. Comparing these coefficients to the overall (unconditional) change

\footnotetext{
${ }^{14}$ See for example Goos, Manning, and Salomons (2014).

${ }^{15}$ These results show very little sensitivity to restricting the sample to independent establishments only; hence they are again not driven by establishments that are part of larger firms.
} 
in specialization probabilities, we can see that more than half of the overall increase in specialization in both non-routine manual and non-routine cognitive tasks occurs within cells defined by industry and establishment characteristics. Changes in the industrial composition play a relatively larger role in explaining the decline in specialization in routine manual occupations, as the coefficient on the 2011 dummy is reduced by around 60\% relative to the unconditional change between 1998 and 2011.

\subsection{Changes in establishment specialization and aggregate po- larization}

We now turn to an analysis of the relationship between the changes in specialization patterns and the changes in aggregate employment shares of different occupations. To do this, we perform a decomposition to determine the contribution of (1) changes in the composition of the establishment population in terms of the occupations that they specialize in, and (2) changes in the intensity of use of different occupations within establishments with different specializations. Specifically, we can write the aggregate employment share in a particular task, say routine manual (RM) as:

$$
E_{t}^{R M}=\sum_{j} e_{j t} E_{j t}^{R M}
$$

where $j \in\{N R C, R C, R M, N R M, X\}$ indexes specialization categories, with $X$ being non-specialized, $e_{j t}$ is the share of aggregate employment in establishments specialized in category $j$ in period $t$, and $E_{j t}^{R M}$ is the (average) routine manual employment share among establishments specialized in $j$ at time $t$. Using this equation, the change in the routine manual employment share between periods $t$ and $t+1, \Delta E_{t+1}^{R M}$, can be decomposed as:

$$
\Delta E_{t+1}^{R M}=\sum_{j} \Delta e_{j, t+1} E_{j t}^{R M}+\sum_{j} e_{j t} \Delta E_{j, t+1}^{R M}+\sum_{j} \Delta e_{j, t+1} \Delta E_{j, t+1}^{R M}
$$

The first component captures changes between specialization categories in the share of total employment that they account for (weighted by each type's initial routine manual employment share). The second component captures changes within specialization categories in their routine manual employment share (weighted by each type's initial size). The third component captures an interaction between the two changes. 
Analogous decompositions can be performed for each of the four tasks ${ }^{16}$

Panel A of Table 6 reproduces the overall changes in the employment shares in each task between 1998 and 2011 in our sample, while Panel B presents the results from the decomposition. For non-routine cognitive occupations, over $75 \%$ of the increase in their employment share comes from a change in the composition of establishments with different specializations, namely the shift towards establishments specializing in non-routine cognitive employment and away from those specializing in routine manual jobs. The remainder is due to the increase in the employment of non-routine cognitive workers in all types of establishments and particularly so in those specializing in this type of occupation, as can be seen in Figure $1{ }^{17}$

The stability of the routine cognitive employment share is the result of very small and opposite changes occurring between and within establishments with different specializations. The individual components of the summation terms in Equation (2) (not reported here) confirm that the the intensity of use of routine cognitive employment declined within all workplaces except in those specialized in these tasks.

For routine manual employment, $85 \%$ of the large decline in employment share is accounted for by changes in the composition of the establishment population in terms of specialization. By considering the individual components of the summation terms in Equation (2), we find that almost two thirds of this is accounted for by the decline in the proportion of workplaces specialized in routine manual tasks. The use of this type of employment has also declined conditional on establishment specialization, contributing a total of $1.7 \mathrm{pp}$ to the decline in the aggregate share.

The modest increase in non-routine manual employment is entirely accounted for by the increase in the proportion of workplaces specializing in such occupations, as captured by the between-specialization component reported in Column (4) of Table

\footnotetext{
${ }^{16}$ This is different from a more standard decomposition of within versus between firm components (as performed by Böckerman et al., 2016; Pekkala Kerr et al., 2015; Harrigan et al., 2015), which we are not able to carry out in our context due to the lack of suitable longitudinal data. Our exercise is motivated by our earlier finding of widespread and increasing occupational specialization. A possible limitation of this approach is that the importance of "between-group" changes might appear large as a result of relatively small changes in employment shares around the $50 \%$ cutoff that would lead firms to change specialization based on our definition. However, we have already seen that the average share of the main occupation is well above $70 \%$, indicating that a change in specialization requires a substantial adjustment for the average firm. Furthermore, if, for example, the decline in the fraction of workplaces specialized in routine occupations was driven by workplaces with initial shares just above the $50 \%$ threshold, then we would expect an increase over time in the lower percentiles of the distribution of the share of routine employment in these workplaces. We find no indication of this in the data.

${ }^{17}$ This is more formally shown by the relative size of the individual components of the summation terms in Equation (2) which are not reported in Table 6 but are available from the authors.
} 
6. The total within-specialization component is small and negative. The individual components of the summation term in Equation (2) show that this is the result of the sum of changes of opposite signs across establishments of different specializations that were already apparent in Figure 1 1 the use of non-routine manual employment has declined in workplaces which do not specialize in these tasks, but has increased in specialized workplaces. This pattern is consistent with an increase in outsourcing of non-routine manual tasks; however, as we show in Section 4.2, we find no clear direct indication of increased trade between firms in these particular tasks.

To determine the extent to which these changes in the composition of establishment specializations are due to changes in industrial composition, we perform a further set of decompositions. Panel $\mathrm{C}$ of Table 6 performs a standard decomposition of the changes in the employment share of each of the four task groups into a between-industry and a within-industry component. As has been documented in the literature, changes in the industrial composition account for an important fraction of the changes in employment shares, but there is also an important role for changes in employment shares in each task within industries. In Panel D we focus exclusively on the within-industry component, in order to determine the extent to which changes in the composition of establishment specializations play a role within industries. Specifically, we perform a decomposition analogous to Equation (2) for the within-industry component only. The results show that the change in specialization composition is the main driver of the within-industry decline in routine manual employment, and also accounts for more than half of the within-industry increase in non-routine cognitive tasks.

Overall these results confirm that the reduction in the fraction of employment in establishments that specialize in routine manual tasks, and the compensating increase

in the fraction of employment in establishments that specialize in non-routine cognitive tasks, have played a major role in driving changes in aggregate occupational shares, both between and within industries. The results also suggest that changes in employment shares conditional on establishment specialization are relatively less important as a driver of the observed aggregate changes.

\section{Technology and outsourcing}

In the previous sections we have documented high and increasing occupational specialization in British workplaces and showed that a large shift in specialization towards 
non-routine occupations acounts for much of the polarized changes in aggregate occupational shares between 1998 and 2011. To what extent are these new findings consistent with the explanation for polarization that has so far received the strongest empirical support in the literature, namely the routine-biased technological change (RBTC) hypothesis? The decline in the demand for routine employment driven by automation could help explain the shift towards specialization in non-routine occupations that we have documented. Indeed, our results suggest that changes in specialization among continuing establishments might have played a significant role in reducing the fraction of workplaces specializing in routine cognitive occupations - as one would expect if technology replaces routine workers in existing workplaces. Also, we find that changes in industry composition and workplace characteristics do not account for much of the increased specialization in non-routine occupations. However, we find no clear indication that the intensity of use of routine employment has declined in workplaces which have remained specialized in such occupations. This contrasts with the argument that workplaces with the largest shares of routine employment face the strongest incentives to automate (Autor and Dorn, 2013; Harrigan et al., 2015; Bessen, 2015). We have also shown that a substantial proportion of new workplaces continue to be specialized in routine cognitive occupations, and that high closure rates have played a major role in driving down the share of workplaces specializing in routine manual occupations (rather than changes among continuing establishments which would more likely occur as a result of workplace-level investments in new technology).

The structure of our data does not allow us to provide direct causal evidence on the role of aggregate technological progress in driving the workplace-level changes that we have documented. However, we are able to exploit rarely available information on the adoption and use of technology at the workplace level to investigate the presence of some of the underlying mechanisms put forward in this literature. In particular, we provide new evidence on the use of technology across workplaces specializing in different occupations as well as on the link between technology adoption and changes in the level and composition of employment in the workplace. This is an additional important contribution of this paper given that existing empirical studies are very rarely able to use direct measures of technology, often resorting instead to an analysis of the patterns over time in the composition of employment of different tasks in order to draw inferences about the underlying trends in technology 18

\footnotetext{
${ }^{18}$ One exception is Graetz and Michaels (2015), who use data from the International Federation of Robotics to study the impact of modern industrial robots at the industry level. See also the pioneering
} 


\subsection{Technology}

Columns (1) to (3) in Panel A of Table 7 show the fraction of workplaces reporting that they have introduced or upgraded to new technologies (including computers) in recent years. In 1998, managers were asked about technology adoption in the previous five years, while in 2004 and 2011 they were asked about adoption in the previous two years 19 Between 1998 and 2004, technology adoption increased markedly only for workplaces specialized in non-routine manual tasks or not specialized at all. In 2011, the proportion of workplaces reporting recent technological change fell significantly presumably as a result of the Great Recession - with the largest declines (of about $30 \%$ ) occurring in routine cognitive workplaces and in non-routine manual ones. In each year, non-routine cognitive workplaces were the most likely to report the adoption of new technology and non-routine manual ones were the least likely.

Columns (4) and (5) show that, overall, the average share of employees using computers increased from just under $48 \%$ in 2004 to over $61 \%$ in 2011 . The increase occurred within all workplaces, but was particularly pronounced in those specializing in manual tasks (which start from relatively low levels of computer usage). While the share using computers remains much higher in cognitive workplaces (reaching 90\% in non-routine cognitive ones in 2011), the gap with manual workplaces has shrunk substantially as the figures more than doubled in non-routine manual workplaces (going from $16 \%$ to over $33 \%$ ) and increased by $40 \%$ in routine manual workplaces (from $26.7 \%$ to $37.6 \%$ ). It is worth emphasizing that these large changes occurred over the span of just seven years. Computer usage therefore appears to be catching up quickly in workplaces specializing in non-routine manual occupations. This is an interesting finding, as these occupations are generally assumed to offer little scope for either complementarity or substitution with regards to new technologies (Autor, 2015). Growth in lower-skilled non-routine manual occupations is instead generally attributed to indirect effects of

work by Autor et al. (2003), who analyze the link between computerization and task changes at the industry level. Gaggl and Wright (2015) are able to identify the causal effects of ICT on worker outcomes by exploiting a tax incentive for ICT investment tailored to small firms in the UK. Other important contributions to the literature which analyze the effects of ICT availability and/or adoption at the establishment or firm level include Doms et al. (1997); Black and Lynch (2001); Bresnahan et al. (2002); Brynjolfsson and Hitt (2003); Bartel et al. (2007) and Akerman et al. (2015).

${ }^{19}$ In all three columns we use only workplaces that have been in operation for at least 5 years, given that in 1998 this question was only asked of this sample. For 2004 and 2011, the results obtained using the full sample are very similar to those reported here. The different time frames of the questions would lead us to expect the 1998 figures to be biased upwards; however, this bias is unlikely to differ according to establishment specialization. 
technology which take place through spillovers or complementarities in consumption between goods and services (Autor and Dorn, 2013; Mazzolari and Ragusa, 2013).

Panel B shows the occupational specialization profile of workplaces with high levels of computer usage (i.e. above the 2004 median value of 60\%) in 2004 and 2011. Interestingly, the figures show that there has been a large increase in the proportion of these workplaces that specialize in non-routine cognitive occupations mostly at the expense of the proportion specializing in routine cognitive ones. The net result is that the fraction of workplaces with high computer use which specialize in any cognitive occupation (whether routine or non-routine) has actually slightly decreased from $73 \%$ to just under 70\%. Meanwhile, the share specializing in non-routine manual occupations has more than doubled from $4 \%$ to over $10 \%$. This is another indication that the importance of technology is increasingly extending beyond the set of occupations generally considered in the literature on RBTC.

Panel $\mathrm{C}$ of Table 7 considers the pessimistic view that argues that the speed of recent technological change is likely to result in a net reduction in employment - a view that has been termed as "new technological anxiety" (Autor, 2015; Mokyr et al., 2015). In particular, we provide estimates of the correlation between reporting the adoption of technology in 1998 and the probability of increasing the level of employment by 2004, conditional on establishment characteristics in the initial period ${ }^{20}$ Column (1) shows that the estimated coefficient is positive and significant at the $5 \%$ level for the whole sample. Although a causal interpretation is clearly not warranted in this setting, this result suggests that efficiency gains associated with technology adoption and leading to employment growth at the establishment level dominate any labor replacing effects of technology. Interestingly, when we break down the sample by task specialization, the positive correlation is statistically significant only for manual workplaces. Hence, we see no evidence that technology adoption reduces employment growth at the workplace level in general, or in workplaces specializing in routine occupations in particular.

Our dataset also provides information on whether, in the last 12 months, the workplace experienced any redundancies for which one of the main reasons was the intro-

\footnotetext{
${ }^{20}$ The 2004 wave of WERS provides information on the change in total employment for all 1998 workplaces that survive and are located in 2004. The analogous relationship for the 2004-2011 period can only be estimated using the limited panel dimension of the survey (551 observations). For that period, we also find a positive relationship between recent technological adoption and subsequent employment growth probabilities conditional on establishment characteristics (coefficient: 0.106), although the effect is not statistically significant (p-value: 0.131 ).
} 
duction of "automation/mechanization/new equipment" ${ }^{21}$ The fraction of workplaces reporting redundancies is around 13\% in 2004 and 18\% in 2011. The proportion of workplaces with reported redundancies that mention automation as one of the main reasons is only $2.3 \%$ and $2.6 \%$ in the two years respectively (or under $0.5 \%$ of the whole sample in both years). Conditioning on the usual establishment characteristics, the correlation between recent adoption of technology and the probability of redundancies in the past 12 months is positive but statistically insignificant, while the correlation with the share of redundancies (as a fraction of employment a year earlier) - conditional on reporting any redundancies - is negative and statistically insignificant. This tentative evidence does not point to a clear relationship between automation and redundancies in the short term.

Table 8 explores the evidence on whether technology adoption is correlated with changes in the occupational composition of employment within the establishment by exploiting the limited panel dimension in the data. The dependent variable is the annualized within-establishment change in the employment share of a given occupational group between waves $t-1$ and $t$, and the main regressor of interest is whether the establishment reports having recently adopted new technologies at the time of the $t-1$ survey. The regression in Column (1) considers the within-establishment change in the non-routine cognitive employment share and, in addition to the technology variable, includes a year dummy only. The regression in Column (2) adds controls for the initial non-routine cognitive employment share within the establishment (in order to control for potential heterogeneities in share changes according to initial conditions), as well as controls for the establishment's industry, region, age, and size in the base period. The remaining columns consider analogous specifications for each of the other occupation groups.

Interestingly, the recent adoption of new technologies is correlated with very little subsequent change in the share of employment in non-routine cognitive occupations within the establishment 22 Surprisingly, the adoption of new technology is associated with an increase in the use of routine tasks within the establishment - although the effect is not statistically significant in the case of routine manual tasks. The strongest

\footnotetext{
${ }^{21}$ Managers are first asked whether the workplace experienced any redundancies in the past 12 months, and then a follow-up questions asks "What have been the main reasons for the redundancies?". A list of possible options is provided, including "automation/mechanization/new equipment". Managers were able to choose all the options that they considered to be applicable.

${ }^{22}$ This is consistent with Doms et al. (1997), who find little correlation between skill upgrading and the adoption of new technologies using longitudinal plant-level data.
} 
effect that we observe is that establishments that adopt new technologies tend to subsequently reduce the share of employment in non-routine manual tasks. Conditional on establishment characteristics, including their initial non-routine manual share, the result in Column (8) implies that the adoption of new technologies is associated with a 1.2 percentage point annual decline in the establishment's share of non-routine manual employment.

Overall, although we acknowledge that our results do not warrant a causal interpretation, the correlations that we identify are puzzling in light of the standard RBTC hypothesis. In the following section, we turn our attention to an alternative mechanism through which technology may be driving the observed changes in specialization patterns, namely by changing the boundaries of the firm. ${ }^{23}$

\subsection{Outsourcing}

New technologies reduce transaction and monitoring costs, thus increasing the incentives for firms to acquire services externally, rather than producing them internally (Abramovsky and Griffith, 2006). The polarization literature has mainly focused on the international aspect of this phenomenon (offshoring), while domestic outsourcing has mostly been considered in terms of its impact on low-skilled service workers (Dube and Kaplan, 2010; Goldschmidt and Schmieder, 2015).

Our results on the importance of increased occupational specialization at the workplace level suggest that domestic outsourcing might also play a role in the observed polarization of the British labor market. Firms that supply services to other firms might exploit economies of specialization to be able to provide these services with fewer employees than what client firms can achieve by internal production. These efficiency gains may in turn lead to higher output demand and therefore higher labor demand for the occupations involved. The effects on the occupational structure, and therefore the specialization profile, of the client firm depend on whether the externally-provided services are substitutes or complements for the existing inputs. For example, a firm might replace its own employees with contractors for cleaning services, while it might contract out certain knowledge-intensive services which complement the work of their

\footnotetext{
${ }^{23}$ An alternative driving force which we do not explicitly focus on in this paper is increased competition induced by international trade. Utar (2014) studies the effect of increased competition from China on the workforce composition of firms in Denmark. A large literature has studied the heterogeneous effects of international trade on workers and local labor markets and the link with overall wage inequality; see for example Autor et al. (2014), Utar (2015) and Helpman et al. (2016).
} 
high-skilled employees.

The data in WERS allow us to provide new insights on the importance of these mechanisms by exploiting rarely available information on both whether the workplace provides goods and services to other businesses and on whether it uses contractors for certain activities.

In terms of the demand for the provision of business services from outside of the firm, Figure 2 documents the evolution over time of the fraction of workplaces who make use of contractors for a set of ten activities. Over $85 \%$ of private sector workplaces used contractors for at least one of the activities already in 1998 and the figure reached $90 \%$ by 2011. Figure 2 plots the evolution of the share of establishments using contractors for each activity, relative to their 1998 levels. It is clear that cognitive activities represented as dashed lines in the figure - have seen the largest increases in the use of contractors. In particular, between 1998 and 2011, the share of workplaces using contractors for computing services and payroll increases by $70 \%$, while those using contractors for training and recruiting increases by $12 \%$ and $21 \%$ respectively. More workplaces also report using contractors for building maintenance and security $(+12 \%$ and $+13 \%$ ) while the figures are either stable or in decline for printing/photocopying, transport of documents or goods, cleaning, and catering ${ }^{24}$ In results not reported here, we find that the use of contractors for cognitive activities also increases considerably in the public sector, further increasing the demand for these types of business services.

The increased used of contractors for cognitive activities is not confined to workplaces specialized in a specific occupational group. This is shown clearly in Figure 3 which plots the changes in the share of workplaces using contractors for each of the four cognitive activities by occupational specialization. The use of contractors for computing services almost doubles in workplaces specializing in cognitive occupations and in non-specialized workplaces, but also increases by more than $50 \%$ in NRM workplaces. Workplaces specializing in cognitive occupations have driven the increased use of contractors for recruiting, but those specializing in NRM occupations have seen the largest proportionate increases in the use of contractors for training and payroll services.

While these results refer only to a limited set of activities for which contractors can be used, they provide a clear indication that there has been an increase in the demand for cognitive business services, while that for manual services (such as cleaning

\footnotetext{
${ }^{24}$ As we report in Appendix Table A.3 by 2011, 32\% of workplaces use contractors for computing services and $29 \%$ for payroll, while building maintenance and cleaning continue to be the activities with the largest shares (at $63 \%$ and $52 \%$ respectively).
} 
and catering) has remained rather stable. The increase in the use of contractors for cognitive activities seems to have occurred in workplaces with different occupational specializations, suggesting that it is not linked to a specific technology of production.

To complement this evidence on the demand side of the market for business services with information on the supply side, we turn to a variable in WERS that records whether a workplace engages in business-to-business (B2B) trade. In particular, mangers are asked whether the workplace provides goods and services to (i) other businesses, (ii) consumers, (iii) other parts of the same organization or (iv) whether the workplace is an administrative office of a larger organization. Managers are able to select multiple answers, and we report the results for the sample that indicate trade with other businesses as one of their answers ${ }^{25}$ The main points also hold when restricting attention to workplaces which trade with other businesses exclusively. Note that since this latter group excludes workplaces that are suppliers for other parts of the same firm, our results are once again not driven by specialization patterns of workplaces within larger organizations.

Panel A of Table 9 documents the proportion of workplaces that engage in B2B trade by their occupational specialization. On the whole the proportion of B2B workplaces remains stable at around $45 \%$ between 2004 and 2011. ${ }^{26}$ The breakdown by specialization in the first two columns shows that the only group that has seen an increase in $\mathrm{B} 2 \mathrm{~B}$ activity (from already high levels) is the NRC one. In the remaining columns we see that the increase has been much larger among new establishments, suggesting that the entry of new NRC workplaces might have been sustained by the growth in trade of cognitive tasks between businesses.

Panel B of Table 9 looks at changes in the occupational specialization within the B2B sector over time. The increase in occupational specialization that we have documented in the aggregate is only observed within the B2B sector where the share of non-specialized establishments drops from $24 \%$ to $15 \% 27$ While the polarization in specialization (i.e the growth in the share of NRC and NRM workplaces) is seen in both groups of establishments, B2B establishments have seen a much stronger shift of the distribution towards specialization in NRC occupations. In fact, over just six

\footnotetext{
${ }^{25}$ For comparability reasons, we focus on 2004 and 2011 only. In 1998, managers could only select one of the available options in the question.

${ }^{26}$ The proportion of workplaces engaging exclusively in B2B also remains stable at around $32 \%$.

${ }^{27}$ The fraction of non-specialized establishments also declines in the B2B sector between 2004 and 2011 when considering specialization at the 1-digit level (from $45 \%$ to $38 \%$ ). In non-B2B establishments, the share remains stable at around $19 \%$.
} 
years, the proportion of NRC workplaces increases by over $70 \%$ (from $21 \%$ to $37 \%$ ) in the B2B sector, overcoming the "Not Specialized" and RM groups to become the largest one in 2011. These findings once again align with the increase in the use of contractors for cognitive activities documented above. The increase in specialization and the shift towards NRC specialization become even more pronounced when results are weighted by employment or if the sample is restricted to workplaces that engage in B2B exclusively. In both of these cases, the only group whose share increases over time is that of workplaces specializing in NRC occupations. This set of results indicate that B2B trade has played a major role in driving the increased specialization in NRC occupations, while trade with consumers has played a relatively more important role in the growth of specialization in NRM occupations ${ }^{28}$

In order to test for the link between changes occurring in the B2B sector and aggregate changes in specialization patterns more formally, we pool the data for 2004 and 2011 and run specialization regressions similar to those reported in Table 5, but including a B2B dummy and its interaction with the time dummy as additional controls. In Panel $\mathrm{C}$ of Table 9, we report the results for the two groups for which we see the largest changes over this period, namely RM and NRC. For the probability of specialization in RM occupations, the inclusion of the B2B indicator and its interaction with the time dummy in Column (2) does not change the estimated coefficient on the time dummy in an important way relative to the result obtained in Column (1) where we control for establishments' industry, region, age, and employment level. However, when we include the $\mathrm{B} 2 \mathrm{~B}$ indicator and its time interaction in the regression for the specialization in NRC occupations, the coefficient on the time dummy drops by $40 \%$, from $+5.9 \mathrm{pp}$ in Column (3) to the statistically insignificant $+3.4 \mathrm{pp}$ in Column (4). In this latter specification, the $\mathrm{B} 2 \mathrm{~B}$ variable attracts a positive coefficient of +0.082 which is statistically significant at the $5 \%$ level; its interaction with the time dummy exhibits a positive but statistically insignificant coefficient. Overall, these results offer some tentative support for the hypothesis that the increase in the proportion of NRC workplaces operating in the $\mathrm{B} 2 \mathrm{~B}$ sector has played an important role in the aggregate increase in the fraction of establishments specializing in NRC occupations.

\footnotetext{
${ }^{28}$ When looking at workplaces engaging in B2B exclusively, the share of NRM workplaces declined from $10.2 \%$ in 2004 to $7.42 \%$ in 2011 , while it increased from $27 \%$ to $30 \%$ in the rest of the private sector.
} 


\section{Conclusions}

This paper offers the first study of job polarization in Great Britain using workplace level data. Exploiting unique features of a dataset spanning thirteen years, we provide new insights on features, implications and potential drivers of job polarization.

We first document widespread occupational specialization in workplaces across Britain. This is not due to the division of work across different workplaces of larger organizations. Strikingly, a substantial proportion of the heterogeneity in specialization occurs within industries and among establishments with similar observable characteristics. This finding cautions against the common practice in the literature of assuming a common technology within industries, which leads to the interpretation of within-industry changes as reflecting changes in technology (see for example Goos et al., 2014). The increase in workplace specialization that we document for Great Britain between 1998 and 2011 is in line with the evidence that occupational concentration increased in the US over the same time period (Handwerker and Spletzer, 2016).

Our second contribution is to document remarkable changes in the specialization profiles of British workplaces which have occurred in the space of just over a decade. We show both a decline in the fraction of non-specialized workplaces and an increase in the fraction of employment concentrated in the main task among specialized establishements, including those specialized in routine tasks. The proportion of private sector workplaces specializing in non-routine tasks increased dramatically from $30 \%$ to almost 50\% between 1998 and 2011. These changes in specialization account for most of the aggregate changes in occupational shares, both between and within industries. The combination of these changes has an important implication which has so far been unnoticed in the literature: job polarization in Great Britain has been associated with a substantial reallocation of non-routine employment towards workplaces that specialize in such occupations. In light of the large body of literature which shows that labor market outcomes for similar workers may differ greatly according to the type of firm that they are employed in (Card et al., 2013; Song et al., 2015; Barth et al., 2016, Helpman et al., 2016), this new finding adds an additional dimension to the complex relationship between job polarization and changes in inequality.

Our data do not allow us to directly test for a causal relationship between routinebiased technological change - the prevailing explanation for job polarization in the literature - and the changes in occupational specialization that we document. We do, however, exploit rarely available information on adoption and use of technology at the 
workplace level to investigate the presence of some of the underlying mechanisms put forward in this literature. Surprisingly, we find no support for the hypothesis that the adoption of technology is correlated with lower subsequent use of routine employment at the workplace level. Instead, we find that technology use is growing fast in workplaces specializing in non-routine manual occupations, which are generally assumed to offer limited scope for either complementarity or substitutability between capital and labor (Autor and Dorn, 2013). Our estimates of the correlation between technology adoption and workplace employment also suggest that any labor-replacing effects of technology are offset by its productivity-enhancing effects which increase the scale of the firm. Relatedly, we find that very few workplaces report redundancies due to automation when asked directly. These results are in line with those of recent studies that find no indication of a negative effect of technology on overall employment levels using occupation, industry and individual level data (Bessen, 2015; Graetz and Michaels, 2015; Gaggl and Wright, 2015).

Technology may be influencing the changes in occupational specialization at the workplace level through mechanisms other than the ones emphasised by the RBTC hypothesis. As Abramovsky and Griffith (2006) show, ICT adoption can increase the incentives for firms to acquire services externally, rather than producing them internally, due to the reduction in transaction and monitoring costs. Using unique information on whether a workplace supplies goods and services to other businesses and on whether it uses contractors, we find no indication of an increase over our sample period in outsourcing of low-skill service tasks - the occupations that have been the focus of studies concerned with the implications of outsourcing for inequality (Dube and Kaplan, 2010; Goldschmidt and Schmieder, 2015). Instead, we document a sharp increase in the share of workplaces using contractors for cognitive activities alongside an increase in the proportion of non-routine cognitive workplaces trading with other businesses, especially among new entrants. The business-to-business sector accounts for all of the increase in specialization and for most of the increase in the share of non-routine cognitive workplaces that we document in the aggregate. Strikingly, the proportion of non-routine cognitive workplaces in the business-to-business sector increases by over $70 \%$ between 2004 and 2011. Overall, there is strongly suggestive evidence that the increased trade in cognitive tasks between establishments has played a central role in defining some of the main features of the polarization process at the workplace level.

Our results open a number of interesting avenues for future research. The extent of heterogeneity in task composition across establishments within industries is striking and 
deserves further analysis in order to understand its drivers. For example, it would be interesting to determine whether establishments that use different occupational mixes produce different types of goods within an industry, or whether there is heterogeneity in the input mix even among firms producing the same type of detailed good. Further understanding the implications of specialization for firms and workers would also be interesting, as well as establishing the link between this heterogeneity and the increased dispersion in wages across establishments documented in recent literature (e.g. Song et al., 2015). Finally, our results on the increasing importance of technology in nonroutine manual workplaces call for a better understanding of the relationship between technology and low-skill employment, while the results highlighting the increase in trade in cognitive tasks between firms open up questions on potential co-drivers of this process (Abraham and Taylor, 1996; Sako, 2006), as well as on the implications for workers' outcomes and inequality. 


\section{References}

Abraham, Katharine G and Susan K Taylor (1996), "Firms' use of outside contractors: Theory and evidence." Journal of Labor Economics, 14, 394-424.

Abramovsky, Laura and Rachel Griffith (2006), "Outsourcing and offshoring of business services: How important is ICT?" Journal of the European Economic Association, 4, 594-601.

Acemoglu, Daron and David Autor (2011), "Skills, tasks and technologies: Implications for employment and earnings." Handbook of Labor Economics, 4, 1043-1171.

Akerman, Anders, Ingvil Gaarder, and Magne Mogstad (2015), "The skill complementarity of broadband internet." The Quarterly Journal of Economics, 130, 1781-1824.

Autor, David H. (2015), "Why are there still so many jobs? The history and future of workplace automation." Journal of Economic Perspectives, 29, 3-30.

Autor, David H. and David Dorn (2013), "The growth of low skill service jobs and the polarization of the U.S. labor market." American Economic Review, 103, 1553-1597.

Autor, David H, David Dorn, and Gordon H Hanson (2015), "Untangling trade and technology: Evidence from local labour markets." The Economic Journal, 125, 621646.

Autor, David H., David Dorn, Gordon H. Hanson, and Jae Song (2014), "Trade adjustment: Worker-level evidence." The Quarterly Journal of Economics, 129, 1799-1860.

Autor, David H., Lawrence F. Katz, and Melissa S. Kearney (2006), "The polarization of the US labor market." The American Economic Review, 96, 189-194.

Autor, David H., Lawrence F. Katz, and Melissa S. Kearney (2008), "Trends in US wage inequality: Revising the revisionists." The Review of Economics and Statistics, 90, 300-323.

Autor, David H., Frank Levy, and Richard J. Murnane (2003), "The skill content of recent technological change: An empirical exploration." Quarterly Journal of Economics, 118, 1279-1333. 
Bartel, Ann P., Casey Ichniowski, and Kathryn Shaw (2007), "How does information technology affect productivity? Plant-level comparisons of product innovation, process improvement, and worker skills." The Quarterly Journal of Economics, 122, $1721-1758$.

Bartelsman, Eric J. and Mark Doms (2000), "Understanding productivity: Lessons from longitudinal microdata." Journal of Economic Literature, 38, 569-594.

Barth, Erling, Alex Bryson, James C. Davis, and Richard Freeman (2016), "It's where you work: Increases in the dispersion of earnings across establishments and individuals in the United States." Journal of Labor Economics, 34, S67-S97.

Bessen, James E (2015), "How computer automation affects occupations: Technology, jobs, and skills." Boston Univ. School of Law, Law and Economics Research Paper.

BIS (2015), "Workplace Employee Relations Survey, 2011." URL http://dx.doi.org/ $10.5255 / \mathrm{UKDA}-\mathrm{SN}-7226-7$.

Black, Sandra E. and Lisa M. Lynch (2001), "How to compete: The impact of workplace practices and information technology on productivity." The Review of Economics and Statistics, 83, 434-445.

Bloom, Nick and John Van Reenen (2011), "Human resource management and productivity." Handbook of Labor Economics, 4, 1697-1767.

Böckerman, Petri, Seppo Laaksonen, and Jari Vainiomäki (2016), “Are jobs more polarized in ICT firms?" IZA Discussion Paper.

Bresnahan, Timothy F., Erik Brynjolfsson, and Lorin M. Hitt (2002), "Information technology, workplace organization, and the demand for skilled labor: Firm-level evidence." The Quarterly Journal of Economics, 117, 339-376.

Brynjolfsson, Erik and Lorin M Hitt (2003), "Computing productivity: Firm-level evidence." Review of Economics and Statistics, 85, 793-808.

Caliendo, Lorenzo, Ferdinando Monte, and Esteban Rossi-Hansberg (2015), "The anatomy of French production hierarchies." Journal of Political Economy, 123, pp. 809-852. 
Card, David, Jörg Heining, and Patrick Kline (2013), "Workplace heterogeneity and the rise of West German wage inequality." The Quarterly Journal of Economics, 128, $967-1015$.

Caroli, Eve and John Van Reenen (2001), "Skill-biased organizational change? Evidence from a panel of British and French establishments." Quarterly Journal of Economics, 1449-1492.

Cortes, Guido Matias (2016), "Where have the middle-wage workers gone? A study of polarization using panel data." Journal of Labor Economics, 34, 63-105.

Doms, Mark, Timothy Dunne, and Kenneth R. Troske (1997), "Workers, wages, and technology." The Quarterly Journal of Economics, 112, 253-290.

Dube, Arindrajit and Ethan Kaplan (2010), "Does outsourcing reduce wages in the lowwage service occupations? Evidence from janitors and guards." Industrial \& Labor Relations Review, 63, 287-306.

Dustmann, Christian and Albrecht Glitz (2015), "How do industries and firms respond to changes in local labor supply?" Journal of Labor Economics, 33, pp. 711-750.

Firpo, S., N. Fortin, and T. Lemieux (2011), "Occupational tasks and changes in the wage structure." University of British Columbia Working Paper.

Gaggl, Paul and Greg C Wright (2015), "A short-run view of what computers do: Evidence from a UK tax incentive." SKOPE Research Paper 123.

Garicano, Luis and Esteban Rossi-Hansberg (2006), "Organization and inequality in a knowledge economy." The Quarterly Journal of Economics, 121, 1383-1435.

Goldschmidt, Deborah and Johannes F Schmieder (2015), "The rise of domestic outsourcing and the evolution of the German wage structure." NBER Working Paper No. 21366.

Goos, M., A. Manning, and A. Salomons (2014), "Explaining job polarization: Routinebiased technological change and offshoring." American Economic Review, 104, 25092526.

Goos, Maarten and Alan Manning (2007), "Lousy and lovely jobs: The rising polarization of work in Britain." The Review of Economics and Statistics, 89, 118-133. 
Graetz, Georg and Guy Michaels (2015), "Robots at work." CEPR Discussion Paper No. DP1047\%.

Green, Francis (2012), "Employee involvement, technology and evolution in job skills: A task-based analysis." Industrial \& Labor Relations Review, 65, 36-67.

Griffith, Rachel, Jonathan Haskel, and Andy Neely (2006), "Why is productivity so dispersed?" Oxford Review of Economic Policy, 22, 513-525.

Handwerker, Elizabeth Weber and James R. Spletzer (2016), "The role of establishments and the concentration of occupations in wage inequality." Inequality: Causes and Consequences, Research in Labor Economics, 43, 167-193.

Harrigan, James, Ariell Reshef, and Farid Toubal (2015), "The march of the techies: Technology, trade, and job polarization in France, 1994-2007." Working Paper.

Helpman, Elhanan, Oleg Itskhoki, Marc-Andreas Muendler, and Stephen J Redding (2016), "Trade and inequality: From theory to estimation." Forthcoming, Review of Economic Studies.

Mas, Alexandre and Enrico Moretti (2009), "Peers at work." American Economic Review, 99, 112-45.

Mazzolari, Francesca and Giuseppe Ragusa (2013), "Spillovers from high-skill consumption to low-skill labor markets." Review of Economics and Statistics, 95, 74-86.

Melitz, Marc J. and Stephen J. Redding (2014), "Heterogeneous firms and trade." Handbook of International Economics, 4.

Michaels, Guy, Ashwini Natraj, and John Van Reenen (2014), "Has ICT polarized skill demand? Evidence from eleven countries over twenty-five years." Review of Economics and Statistics, 96, 60-77.

Mokyr, Joel, Chris Vickers, and Nicolas L. Ziebarth (2015), "The history of technological anxiety and the future of economic growth: Is this time different?" Journal of Economic Perspectives, 29, 31-50.

Pekkala Kerr, S., T. Maczulskij, and M. Maliranta (2015), "Within and between firm trends in job polarization: Role of globalization and technology." Working Paper. 
Sako, Mari (2006), "Outsourcing and offshoring: Implications for productivity of business services." Oxford Review of Economic Policy, 22, 499-512.

Salvatori, Andrea (2015), "The anatomy of job polarisation in the UK." Technical report, IZA Discussion Papers.

Song, Jae, David J. Price, Fatih Guvenen, Nicholas Bloom, and Till von Wachter (2015), "Firming up inequality." Working Paper 21199, National Bureau of Economic Research.

Spitz-Oener, Alexandra (2006), "Technical change, job tasks, and rising educational demands: Looking outside the wage structure." Journal of Labor Economics, 24, 235-270.

Utar, Hale (2014), "When the floodgates open: "Northern" firms' response to removal of trade quotas on Chinese goods." American Economic Journal: Applied Economics, 6, 226-50.

Utar, Hale (2015), "Workers beneath the floodgates: Impacts of low-wage import competition and workers' adjustment." Working Paper. 
Figure 1: Composition of employment

\section{Composition of employment by establishment specialization}
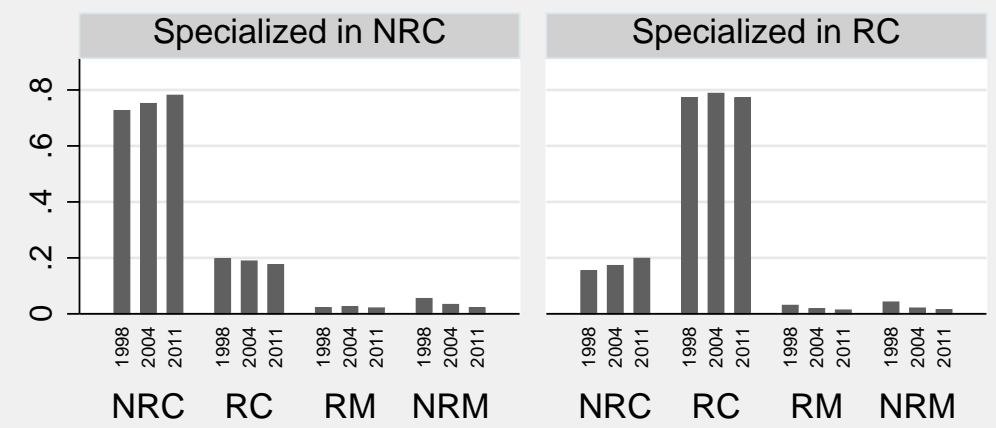

Specialized in RM

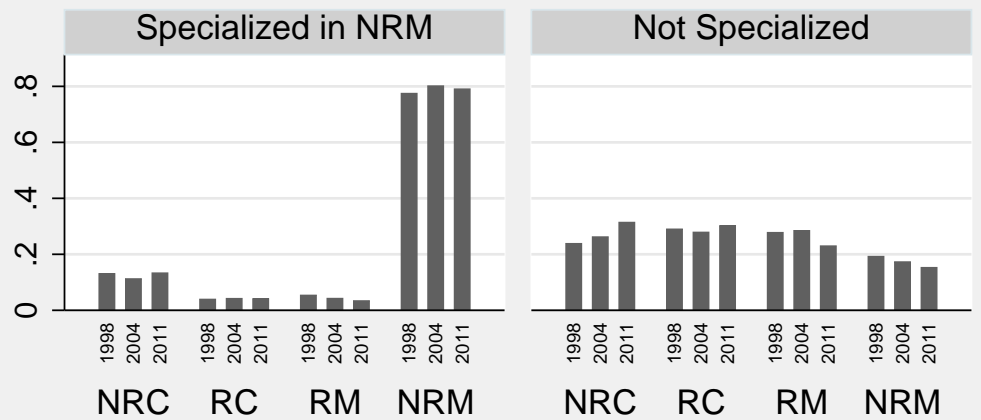

Establishment weights

Private Sector workplaces with more than 10 employees. 
Figure 2: Changes in shares of workplaces using contractors for different activities.

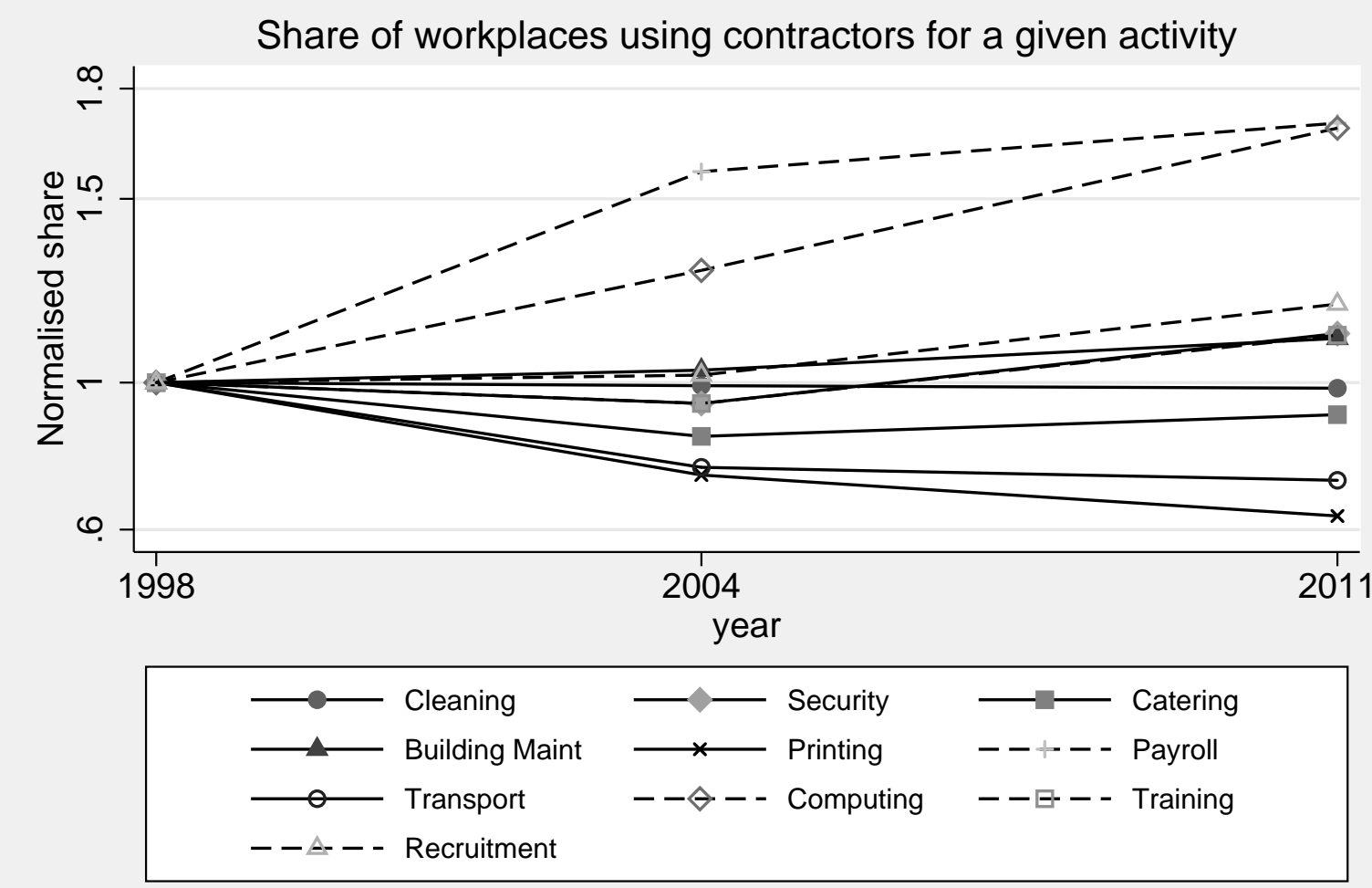

Private sector workplaces with at least 10 employees.

Establishment weights. 
Figure 3: Changes in shares of workplaces using contractors for cognitive activities by specialization

\section{Share using contractors for given activity by specialization}
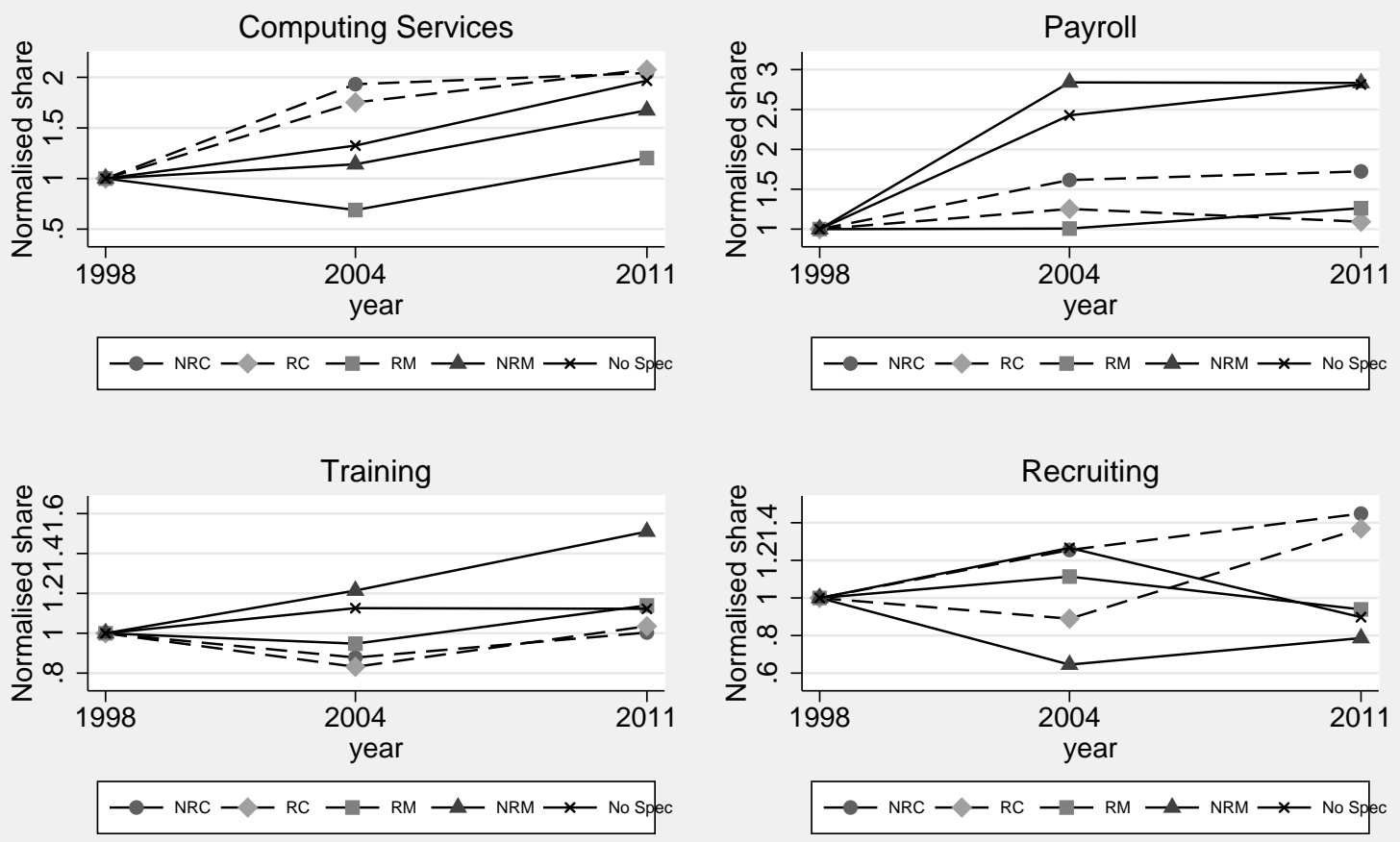

Private sector workplace with at least 10 employees Establishment weights 
Table 1: Employment shares by occupational group

\begin{tabular}{lcccc} 
& NRC & RC & RM & NRM \\
\cline { 2 - 5 }$(1)$ & $(2)$ & $(3)$ & $(4)$ \\
\hline Panel A: Full Sample \\
$\mathbf{1 9 9 8}$ & 0.30 & 0.25 & 0.23 & 0.21 \\
$\mathbf{2 0 0 4}$ & 0.32 & 0.29 & 0.17 & 0.22 \\
$\mathbf{2 0 1 1}$ & 0.39 & 0.27 & 0.13 & 0.21 \\
\hline Panel B: Public Sector \\
$\mathbf{1 9 9 8}$ & 0.45 & 0.20 & 0.07 & 0.28 \\
$\mathbf{2 0 0 4}$ & 0.49 & 0.21 & 0.05 & 0.25 \\
$\mathbf{2 0 1 1}$ & 0.50 & 0.23 & 0.03 & 0.23 \\
\hline Panel & C: Private Sector \\
$\mathbf{1 9 9 8}$ & 0.24 & 0.28 & 0.31 & 0.18 \\
$\mathbf{2 0 0 4}$ & 0.27 & 0.31 & 0.20 & 0.21 \\
$\mathbf{2 0 1 1}$ & 0.35 & 0.28 & 0.17 & 0.20 \\
\hline \hline
\end{tabular}

Workplaces with at least 10 employees.

Table 2: Establishment specialization

\begin{tabular}{ccc|ccc}
\multicolumn{3}{c}{$\begin{array}{c}\text { Proportion of } \\
\text { establishments }\end{array}$} & \multicolumn{3}{c}{$\begin{array}{c}\text { Proportion of } \\
\text { employment }\end{array}$} \\
\hline 1998 & 2004 & 2011 & 1998 & 2004 & 2011 \\
\hline$(1)$ & $(2)$ & $(3)$ & $(4)$ & $(5)$ & $(6)$ \\
\hline
\end{tabular}

\begin{tabular}{lccc|ccc}
\hline Panel A: Private Sector & \multicolumn{5}{l|}{} \\
Specialized in NRC & 16.0 & 15.2 & 25.4 & 15.5 & 18.7 & 31.1 \\
Specialized in RC & 28.7 & 29.0 & 23.7 & 21.3 & 26.4 & 21.6 \\
Specialized in RM & 24.7 & 18.5 & 15.3 & 31.8 & 20.0 & 16.8 \\
Specialized in NRM & 13.9 & 21.7 & 23.3 & 15.3 & 20.7 & 20.0 \\
Not Specialized & 16.7 & 15.6 & 12.4 & 16.1 & 14.3 & 10.4 \\
\hline Panel B: Private Sector Independent Establishments & \\
Specialized in NRC & 16.2 & 14.1 & 28.9 & 18.5 & 16.5 & 36.2 \\
Specialized in RC & 16.3 & 15.6 & 14.4 & 10.3 & 13.0 & 9.8 \\
Specialized in RM & 35.5 & 23.7 & 22.2 & 29.1 & 24.4 & 20.3 \\
Specialized in NRM & 17.9 & 29.7 & 20.7 & 27.7 & 30.5 & 20.9 \\
Not Specialized & 14.1 & 16.9 & 13.8 & 14.4 & 15.6 & 12.8 \\
\hline \hline
\end{tabular}

Note: Proportion of employment refers to the fraction of total employment within each establishment type. 
Table 3: Specialization Composition of Entering, Exiting, and Continuing Establishments

Panel A: 1998-2004

\begin{tabular}{lcc|cc} 
& & & \multicolumn{2}{c}{ Continuing } \\
& Exit & Entry & 1998 & 2004 \\
\cline { 2 - 5 } & $(1)$ & $(2)$ & $(3)$ & $(4)$ \\
\hline Specialized in NRC & 13.67 & 25.24 & 16.34 & 13.88 \\
Specialized in RC & 13.18 & 24.91 & 32.32 & 29.04 \\
Specialized in RM & 31.43 & 10.64 & 23.23 & 20.45 \\
Specialized in NRM & 14.74 & 27.82 & 13.61 & 19.83 \\
Not Specialized & 26.99 & 11.39 & 14.49 & 16.80 \\
\hline
\end{tabular}

Panel B: 2004-2011

\begin{tabular}{lcc|cc} 
& & & \multicolumn{2}{c}{ Continuing } \\
& Exit & Entry & 2004 & 2011 \\
\cline { 2 - 5 } & $(1)$ & $(2)$ & $(3)$ & $(4)$ \\
\hline Specialized in NRC & 14.37 & 22.41 & 15.31 & 26.38 \\
Specialized in RC & 18.94 & 26.18 & 31.73 & 22.07 \\
Specialized in RM & 24.41 & 11.87 & 16.65 & 16.59 \\
Specialized in NRM & 23.56 & 24.63 & 21.57 & 23.08 \\
Not Specialized & 18.71 & 14.91 & 14.74 & 11.87 \\
\hline \hline
\end{tabular}


Table 4: Establishment specialization by broad industry

\begin{tabular}{lccc|ccc} 
& \multicolumn{3}{c}{ Manufacturing } & \multicolumn{3}{c}{ Services } \\
\cline { 2 - 7 } & 1998 & 2004 & 2011 & 1998 & 2004 & 2011 \\
\cline { 2 - 7 } & $(1)$ & $(2)$ & $(3)$ & $(4)$ & $(5)$ & $(6)$ \\
\hline Specialized in NRC & 5.9 & 10.9 & 16.0 & 18.2 & 16.0 & 26.6 \\
Specialized in RC & 3.3 & 3.7 & 3.0 & 34.2 & 33.3 & 26.4 \\
Specialized in RM & 65.9 & 54.9 & 56.4 & 15.8 & 12.3 & 9.9 \\
Specialized in NRM & 2.2 & 3.5 & 2.1 & 16.4 & 24.8 & 26.0 \\
Not Specialized & 22.7 & 27.2 & 22.6 & 15.4 & 13.6 & 11.1 \\
\hline \hline
\end{tabular}


Table 5: OLS regression of specialization dummies on workplace characteristics.

\begin{tabular}{|c|c|c|c|c|}
\hline & \multicolumn{4}{|c|}{ Dependent var: Prob of specializing in... } \\
\hline & $\mathrm{NRC}$ & $\mathrm{RC}$ & $\mathrm{RM}$ & NRM \\
\hline & $(1)$ & $(2)$ & $(3)$ & $(4)$ \\
\hline D2004 & $\begin{array}{l}-0.0163 \\
(0.0198)\end{array}$ & $\begin{array}{l}-0.0281 \\
(0.0258)\end{array}$ & $\begin{array}{l}-0.0199 \\
(0.0223)\end{array}$ & $\begin{array}{c}0.0636^{* *} \\
(0.0199)\end{array}$ \\
\hline D2011 & $\begin{array}{c}0.0507^{* *} \\
(0.0213)\end{array}$ & $\begin{array}{c}-0.0435^{*} \\
(0.0254)\end{array}$ & $\begin{array}{c}-0.0376^{*} \\
(0.0214)\end{array}$ & $\begin{array}{c}0.0514^{* *} \\
(0.0213)\end{array}$ \\
\hline \multicolumn{5}{|c|}{ Establishment Age (years): } \\
\hline $7-13$ & $\begin{array}{l}0.0116 \\
(0.0264)\end{array}$ & $\begin{array}{c}-0.0693^{* *} \\
(0.0336)\end{array}$ & $\begin{array}{c}0.0623^{* *} \\
(0.0295)\end{array}$ & $\begin{array}{l}0.0232 \\
(0.0299)\end{array}$ \\
\hline $14-20$ & $\begin{array}{l}0.0182 \\
(0.0284)\end{array}$ & $\begin{array}{c}-0.00271 \\
(0.0346)\end{array}$ & $\begin{array}{l}0.0249 \\
(0.0242)\end{array}$ & $\begin{array}{c}-0.0277 \\
(0.0263)\end{array}$ \\
\hline $21-34$ & $\begin{array}{c}0.00162 \\
(0.0260)\end{array}$ & $\begin{array}{c}-0.0354 \\
(0.0338)\end{array}$ & $\begin{array}{l}0.0266 \\
(0.0320)\end{array}$ & $\begin{array}{c}-0.0271 \\
(0.0257)\end{array}$ \\
\hline 25 or more & $\begin{array}{c}-0.00796 \\
(0.0268)\end{array}$ & $\begin{array}{c}0.0688^{*} \\
(0.0374)\end{array}$ & $\begin{array}{l}0.0308 \\
(0.0317)\end{array}$ & $\begin{array}{c}-0.0841^{* *} \\
(0.0313)\end{array}$ \\
\hline \multicolumn{5}{|c|}{ Establishment Size: } \\
\hline $25-49$ & $\begin{array}{l}-0.0301 \\
(0.0186)\end{array}$ & $\begin{array}{c}-0.0531^{* *} \\
(0.0214)\end{array}$ & $\begin{array}{l}-0.0102 \\
(0.0223)\end{array}$ & $\begin{array}{c}0.0744^{* * *} \\
\quad(0.0182)\end{array}$ \\
\hline $50-99$ & $\begin{array}{c}-0.00388 \\
(0.0206)\end{array}$ & $\begin{array}{c}-0.0700^{* *} \\
(0.0219)\end{array}$ & $\begin{array}{l}0.0133 \\
(0.0211)\end{array}$ & $\begin{array}{c}0.0745^{* * *} \\
\quad(0.0192)\end{array}$ \\
\hline 100-199 & $\begin{array}{c}-0.0603^{* *} \\
(0.0229)\end{array}$ & $\begin{array}{c}-0.0633^{* *} \\
(0.0241)\end{array}$ & $\begin{array}{c}0.000847 \\
(0.0233)\end{array}$ & $\begin{array}{c}0.129 * * * \\
(0.0214)\end{array}$ \\
\hline 200 or more & $\begin{array}{l}-0.0271 \\
(0.0219)\end{array}$ & $\begin{array}{c}-0.101^{* * *} \\
(0.0237)\end{array}$ & $\begin{array}{l}0.0203 \\
(0.0229)\end{array}$ & $\begin{array}{c}0.127^{* * * *} \\
(0.0173)\end{array}$ \\
\hline Cons & $\begin{array}{c}0.253^{* *} \\
(0.0968)\end{array}$ & $\begin{array}{c}0.242^{* *} \\
(0.0834)\end{array}$ & $\begin{array}{c}0.139 * * \\
(0.0563)\end{array}$ & $\begin{array}{c}0.291^{* * *} \\
(0.0830)\end{array}$ \\
\hline Region & Yes & Yes & Yes & Yes \\
\hline 2-digit Ind & Yes & Yes & Yes & Yes \\
\hline Obs. & 4390 & 4390 & 4390 & 4390 \\
\hline$R^{2}$ & 0.341 & 0.390 & 0.397 & 0.355 \\
\hline
\end{tabular}

Note: Robust Standard Errors in parenthesis. 
Table 6: Decomposition of changes in occupational employment shares

Panel A: Overall Change

\begin{tabular}{lcccc} 
& NRC & RC & RM & NRM \\
\cline { 2 - 5 } & $(1)$ & $(2)$ & $(3)$ & $(4)$ \\
\hline 1998 & 0.2420 & 0.2762 & 0.3059 & 0.1758 \\
2011 & 0.3508 & 0.2807 & 0.1687 & 0.1998 \\
Change & 0.1087 & 0.0045 & -0.1372 & 0.0240 \\
\hline
\end{tabular}

Panel B: Decomposition of the Overall Change Between and Within Specialization Categories

\begin{tabular}{lcccc} 
& NRC & RC & RM & NRM \\
\cline { 2 - 5 } & $(1)$ & $(2)$ & $(3)$ & $(4)$ \\
\hline Between Specialization & 0.0821 & 0.0083 & -0.1170 & 0.0271 \\
Within Specialization & 0.0228 & -0.0004 & -0.0173 & -0.0051 \\
Interaction & 0.0036 & -0.0042 & -0.0011 & 0.0017 \\
\hline
\end{tabular}

Panel C: Decomposition of the Overall Change Between and Within Industries

\begin{tabular}{lcccc} 
& $\mathrm{NRC}$ & $\mathrm{RC}$ & $\mathrm{RM}$ & $\mathrm{NRM}$ \\
\cline { 2 - 5 } & $(1)$ & $(2)$ & $(3)$ & $(4)$ \\
\hline Between Industries & 0.0378 & 0.0000 & -0.0858 & 0.0480 \\
Within Industries & 0.0750 & 0.0040 & -0.0542 & -0.0248 \\
Interaction & -0.0041 & 0.0005 & 0.0028 & 0.0008 \\
\hline
\end{tabular}

Panel D: Decomposition of the Within Industry Component Between and Within Specialization Categories

\begin{tabular}{lcccc} 
& NRC & RC & RM & NRM \\
\cline { 2 - 5 } & $(1)$ & $(2)$ & $(3)$ & $(4)$ \\
\hline Between Specialization & 0.0382 & 0.0154 & -0.0551 & -0.0100 \\
Within Specialization & 0.0232 & -0.0061 & -0.0093 & -0.0163 \\
Interaction & 0.0136 & -0.0054 & 0.0103 & 0.0015 \\
\hline \hline
\end{tabular}


Table 7: Technology use and adoption

Panel A: Technology use and adoption by specialization

\begin{tabular}{|c|c|c|c|c|c|}
\hline & \multicolumn{3}{|c|}{$\begin{array}{l}\text { Fraction reporting } \\
\text { technology adoption }\end{array}$} & \multicolumn{2}{|c|}{$\begin{array}{l}\text { \% Employees } \\
\text { using PC }\end{array}$} \\
\hline & 1998 & 2004 & 2011 & 2004 & 2011 \\
\hline & Past 5 years & \multicolumn{2}{|c|}{ Past 2 years } & & \\
\hline & $(1)$ & $(2)$ & $(3)$ & (4) & $(5)$ \\
\hline Specialized in NRC & 0.84 & 0.83 & 0.68 & 82.6 & 90.7 \\
\hline Specialized in $\mathrm{RC}$ & 0.75 & 0.73 & 0.51 & 63.9 & 68.5 \\
\hline Specialized in RM & 0.76 & 0.72 & 0.58 & 26.7 & 37.6 \\
\hline Specialized in NRM & 0.55 & 0.62 & 0.40 & 16.2 & 33.2 \\
\hline Not specialized & 0.59 & 0.79 & 0.63 & 53.3 & 67.3 \\
\hline All specializations & 0.71 & 0.73 & 0.56 & 47.9 & 61.1 \\
\hline
\end{tabular}

Panel B: Specialization among workplaces with PC use $>60 \%$

\begin{tabular}{lcc} 
& 2004 & 2011 \\
\cline { 2 - 3 } & $(1)$ & $(2)$ \\
\hline Specialized in NRC & 30.59 & 41.90 \\
Specialized in RC & 42.41 & 27.73 \\
Specialized in RM & 5.83 & 5.47 \\
Specialized in NRM & 4.19 & 10.11 \\
Not Specialized & 16.98 & 14.78 \\
\hline
\end{tabular}

Panel C: Probability of increasing employment (1998-2004)

Sample restricted to establishments specialized in...

\begin{tabular}{lccccc} 
& All & NRC & RC & RM & NRM \\
\cline { 2 - 6 } & $(1)$ & $(2)$ & $(3)$ & $(4)$ & $(5)$ \\
\hline TechChange (1998) & $0.191^{* *}$ & -0.147 & 0.229 & $0.347^{* * *}$ & $0.304^{* * *}$ \\
& $(0.0630)$ & $(0.118)$ & $(0.142)$ & $(0.0868)$ & $(0.0817)$ \\
Estab Charact & & & & & \\
Obs. & Yes & Yes & Yes & Yes & Yes \\
$R^{2}$ & 1228 & 208 & 314 & 323 & 195 \\
\hline \hline
\end{tabular}

Note: Private sector workplaces with at least 10 employees. Establishment weights used. In Panel A, Columns (1) to (3) use workplaces aged at least 5 for consistency with 1998 . In Panel B, the $60 \%$ threshold is the median value of the share using PC in 2004. In Panel C, all regressions include controls for age, employment size, region and 2-digit industry dummies. The regressions use the cross-sectional sample of 1998 which received a follow-up questionnaire in 2004 to establish survival and employment size. 


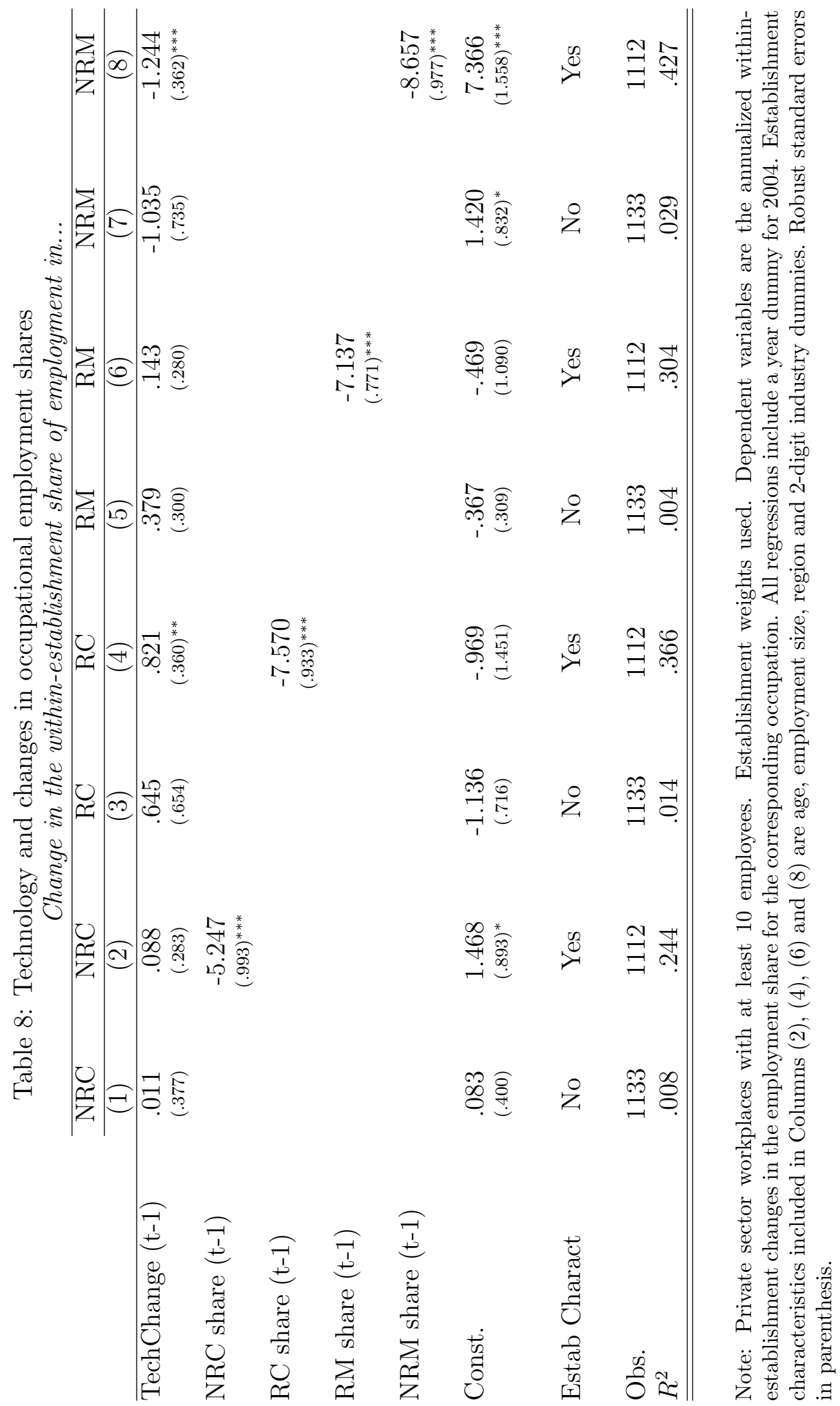


Table 9: Business to business (B2B) trade and occupational specialization

Panel A: Fraction of establishments in B2B sector by specialization

\begin{tabular}{lcc|cc} 
& \multicolumn{2}{c}{ All workplaces } & \multicolumn{2}{c}{ New workplaces } \\
& 2004 & 2011 & 2004 & 2011 \\
\cline { 2 - 5 } & $(1)$ & $(2)$ & $(3)$ & $(4)$ \\
\hline Specialized in NRC & 0.63 & 0.67 & 0.54 & 0.82 \\
Specialized in RC & 0.18 & 0.18 & 0.22 & 0.10 \\
Specialized in RM & 0.81 & 0.82 & 0.83 & 0.86 \\
Specialized in NRM & 0.23 & 0.24 & 0.37 & 0.35 \\
Not Specialized & 0.69 & 0.56 & 0.67 & 0.37 \\
All Specializations & 0.45 & 0.46 & 0.46 & 0.45 \\
\hline
\end{tabular}

Panel B: Specialization shares by B2B sector

Non-B2B

B2B

\begin{tabular}{lcc|cc} 
& 2004 & 2011 & 2004 & 2011 \\
\cline { 2 - 5 } & $(1)$ & $(2)$ & $(3)$ & $(4)$ \\
\hline Specialized in NRC & 10.41 & 15.65 & 21.06 & 36.74 \\
Specialized in RC & 43.81 & 36.16 & 11.20 & 9.17 \\
Specialized in RM & 6.41 & 5.16 & 32.98 & 26.99 \\
Specialized in NRM & 30.49 & 32.91 & 11.16 & 12.09 \\
Not Specialized & 8.88 & 10.12 & 23.60 & 15.02 \\
\hline
\end{tabular}

Panel C: Regressions for the probability of specialization (2004-2011)

\begin{tabular}{lcc|cc} 
& \multicolumn{2}{c}{$\operatorname{Pr}(\mathrm{RM}$ specialization $)$} & \multicolumn{2}{c}{$\operatorname{Pr}(\mathrm{NRC}$ specialization $)$} \\
\cline { 2 - 5 } & $(1)$ & $(2)$ & $(3)$ & $(4)$ \\
\hline D2011 & $-0.0352^{* *}$ & $-0.0338^{*}$ & $0.0589^{* *}$ & 0.0342 \\
& $(0.0172)$ & $(0.0186)$ & $(0.0206)$ & $(0.0247)$ \\
B2B & & $0.103^{* *}$ & & $0.0824^{* *}$ \\
& & $(0.0315)$ & & $(0.0355)$ \\
B2B x D2011 & & -0.00241 & & 0.0543 \\
& & $(0.0354)$ & & $(0.0413)$ \\
Estab Charact & Yes & Yes & Yes & Yes \\
Obs. & & & & \\
$R^{2}$ & 3383 & 3383 & 3383 & 3383 \\
& 0.382 & 0.393 & 0.268 & 0.279 \\
\hline
\end{tabular}

Note: Private sector workplaces with at least 10 employees. Establishment weights used. Establishment characteristics in Panel $\mathrm{C}$ are age, employment size, region and 2-digit industry dummies. Robust standard errors in parenthesis. 


\author{
Online Appendix for: \\ "Delving into the Demand Side: Changes in Workplace \\ Specialization and Job Polarization" \\ Guido Matias Cortes (University of Manchester and RCEA) \\ Andrea Salvatori (ISER, University of Essex and IZA)
}

\title{
Appendix A Weighting in WERS
}

WERS employs a complex sampling design which involves stratification, unequal sampling fractions across strata, sampling without replacement and post-stratification. The technical documentation for the 2011 wave dropped the previous recommendation of specifying a stratification variable when using statistical software to account for such complex design. This is based on the observation that corrections for stratification (or finite population corrections) have very limited practical impacts on standard errors produced using WERS data.

Along with the 2011 data, a revised set of weights for 2004 was released which were computed using the same approach to non-response adjustment adopted for the 2011 data. We experimented with a number of regressions to see if different versions of the 2004 weights made any appreciable difference and we concluded that they do not (whether we used employment or establishment weights). As a result, we present results using the most recent version of the 2004 weights. For 1998, we also use the most recent version of the weights which came with the release of the subsequent wave of WERS in 2004.

\section{Appendix B Definition of occupations and compu- tation of employment shares}

Information is available on employment within nine different occupational groups at each establishment in each wave. Managers are given an Employees Profile Questionnaire ahead of the actual interview so that they can look up the figures if necessary. The questionnaire includes a definition of what is meant by each occupational group. 
These descriptions are identical in 2004 and 2011 and there are only minor differences between 1998 and the other two waves which we now discuss briefly.

In 1998, "police, prison, and fire officers, customs and excise officers" are mentioned as examples within the "Protective and personal service occupations" group, while in 2004 and 2011 junior officers are included in "Associate professional and technical occupations" and senior officers in "Managers and senior officials". In terms of our classification this means that these occupations are moved from the non-routine manual group to the non-routine cognitive group. They might therefore bias the change in NRC employment upwards and that in NRM employment downward between 1998 and 2004. Exploiting the availability of detailed occupational coding for the largest occupational group in the workplace, we can establish that in 2004 and 2011 there are only 32 and 55 workplaces respectively with more than 10 employees in which one of these occupational groups is the largest. The figures drop to 1 and 3 respectively when the sample is restricted to the private sector. This suggests that this is likely to be a minor issue for the whole sample and an entirely negligible one for the private sector sample.

In 1998, "hairdressing" was mentioned as an example in the "crafts and skilled service occupations" while in 2004 it was mentioned under "caring, leisure, and other personal service occupations". Hence, in terms of our classification, this implies a movement from the routine manual group to the non-routine manual one. The impact of this change is likely to be very small: keeping in mind that we always restrict the sample to workplaces with more than 10 employees, using the detailed codes for the largest occupational group we see that the number of workplaces dominated by hairdressers was 7 in 2004 and 9 in 2011 - and the average size of the workplace was around 18 employees in each year.

A change that has no impact on our results given our classification is the move of "protective services" (i.e. traffic wardens and security guards) between the two occupational groups which we include in the non-routine manual group.

We have information on the absolute number of employees in each of the nine occupational groups and then, as a separate variable, the total number of employees. There are very few missing values or discrepancies between the total reported number of employees and the total obtained as the sum of occupations. We only use workplaces for which we do not have these issues. In particular, a workplace is in our sample if:

1. It has valid information (no missing values) on all the occupational groups (i.e. workplaces with a missing value for any occupation are discarded); 
2. The sum of employment across occupations is within $5 \%$ of the total reported employment. For those workplaces within the $5 \%$ tolerance interval, we compute the shares using the total based on the sum across occupations. The latter is also the total employment variable we use.

The actual number of workplaces lost due to these rules is small. In 1998, only 26 workplaces do not have valid information for each occupation and another 17 have large discrepancies between the two measures of total employment. In 2004, we lose 19/2295 workplaces due to non-valid information on at least one occupation and 44 are lost due to significant discrepancies in total employment. In 2011, 43/2680 are lost due to non-valid occupation data and 1 is lost due to the significant discrepancy in total employment. 


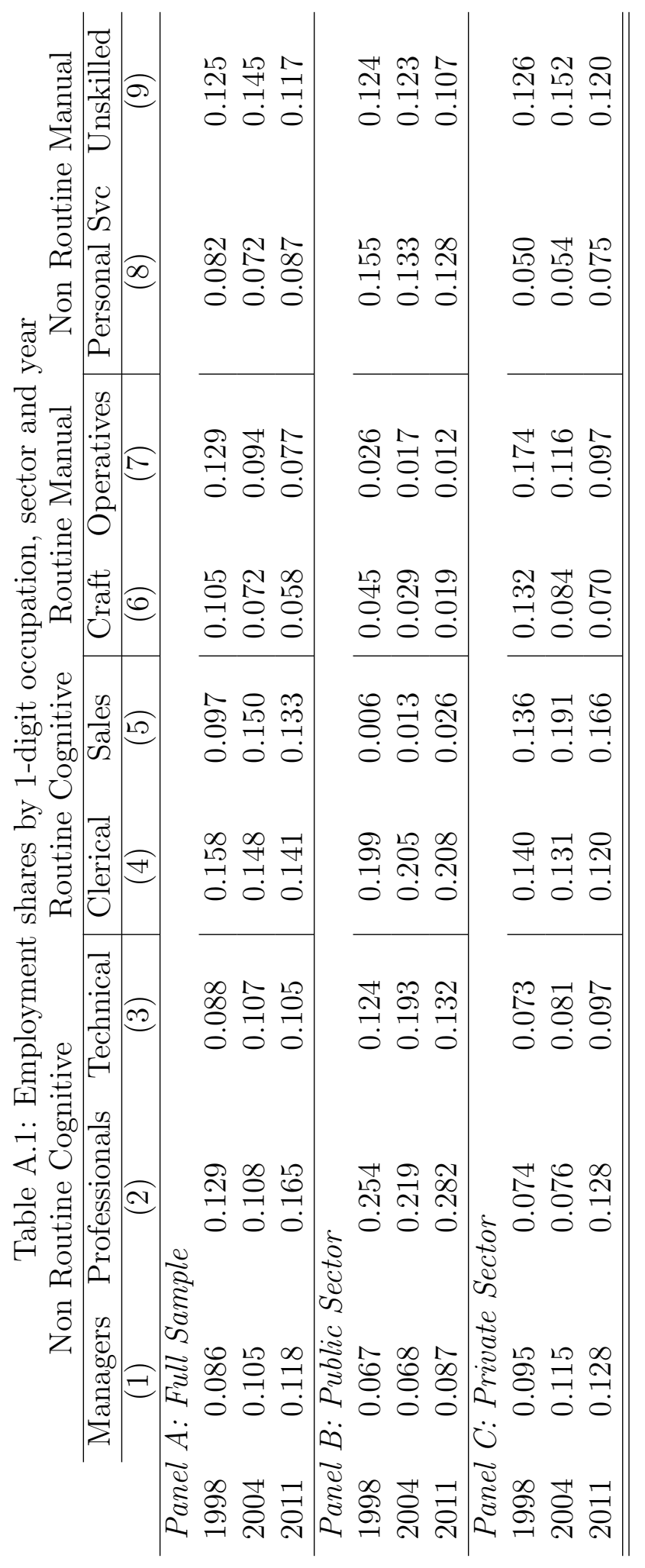


Table A.2: Establishment specialization in 1-digit occupations, private sector

\begin{tabular}{lccc|ccc} 
& \multicolumn{3}{c}{$\begin{array}{c}\text { Proportion of } \\
\text { establishments }\end{array}$} & \multicolumn{3}{c}{$\begin{array}{c}\text { Proportion of } \\
\text { employment }\end{array}$} \\
\cline { 2 - 7 } & 1998 & 2004 & 2011 & 1998 & 2004 & 2011 \\
\cline { 2 - 7 } & $(1)$ & $(2)$ & $(3)$ & $(4)$ & $(5)$ & $(6)$ \\
\hline Non-Routine Cognitive & \multicolumn{3}{c}{} & & & \\
Managers & 2.3 & 0.5 & 0.8 & 1.1 & 0.6 & 0.9 \\
Professionals & 5.2 & 2.8 & 7.8 & 3.5 & 4.4 & 10.0 \\
Technical & 2.4 & 3.3 & 5.7 & 3.2 & 4.7 & 5.2 \\
Routine Cognitive & & & & & & \\
Clerical & 7.1 & 7.0 & 5.7 & 6.0 & 6.1 & 4.6 \\
Sales & 17.3 & 18.4 & 15.6 & 11.8 & 16.4 & 13.8 \\
Routine Manual & & & & & & \\
Craft & 12.7 & 6.8 & 6.4 & 8.5 & 5.1 & 4.4 \\
Operatives & 8.2 & 8.8 & 7.2 & 18.1 & 11.5 & 10.7 \\
Non-Routine Manual & & & & & \\
Personal services & 5.8 & 8.3 & 9.8 & 4.6 & 6.1 & 7.8 \\
Unskilled & 6.0 & 12.8 & 13.0 & 8.8 & 13.9 & 12.0 \\
Not Specialized & & & & & & \\
None & 33.1 & 31.4 & 28.0 & 34.4 & 31.3 & 30.8 \\
\hline \hline
\end{tabular}

Table A.3: Share of workplaces using contractors for a given activity

\begin{tabular}{lccc}
\hline \hline & 1998 & 2004 & 2011 \\
\hline Cleaning & 0.53 & 0.52 & 0.52 \\
Security & 0.31 & 0.30 & 0.36 \\
Catering & 0.11 & 0.10 & 0.10 \\
Building Maint & 0.56 & 0.58 & 0.63 \\
Printing & 0.22 & 0.16 & 0.14 \\
Payroll & 0.17 & 0.27 & 0.29 \\
Transport & 0.40 & 0.31 & 0.30 \\
Computing & 0.19 & 0.25 & 0.32 \\
Training & 0.35 & 0.33 & 0.40 \\
Recruitment & 0.12 & 0.13 & 0.15 \\
Filling Vac & 0.22 & 0.15 & 0.15 \\
\hline \hline
\end{tabular}

Note: Private sector workplaces with at least 10 employees. Establishment weights used. 